\title{
Oxidation of KCNB1 Potassium Channels Causes Neurotoxicity and Cognitive Impairment in a Mouse Model of Traumatic Brain Injury
}

\author{
Wei Yu, Randika Parakramaweera, Shavonne Teng, ${ }^{-M a n a s a}$ Gowda, Yashsavi Sharad, Smita Thakker-Varia, \\ Janet Alder, and Federico Sesti \\ Department of Neuroscience and Cell Biology, Rutgers University, Robert Wood Johnson Medical School, Piscataway, New Jersey 08854
}

The delayed rectifier potassium $\left(\mathrm{K}^{+}\right)$channel KCNB1 (Kv2.1), which conducts a major somatodendritic current in cortex and hippocampus, is known to undergo oxidation in the brain, but whether this can cause neurodegeneration and cognitive impairment is not known. Here, we used transgenic mice harboring human KCNB1 wild-type (Tg-WT) or a nonoxidable C73A mutant (Tg-C73A) in cortex and hippocampus to determine whether oxidized KCNB1 channels affect brain function. Animals were subjected to moderate traumatic brain injury (TBI), a condition characterized by extensive oxidative stress. Dasatinib, a Food and Drug Administration-approved inhibitor of Src tyrosine kinases, was used to impinge on the proapoptotic signaling pathway activated by oxidized KCNB1 channels. Thus, typical lesions of brain injury, namely, inflammation (astrocytosis), neurodegeneration, and cell death, were markedly reduced in $\mathrm{Tg}$-C73A and dasatinib-treated non- $\mathrm{Tg}$ animals. Accordingly, $\mathrm{Tg}$-C73A mice and non- $\mathrm{Tg}$ mice treated with dasatinib exhibited improved behavioral outcomes in motor (rotarod) and cognitive (Morris water maze) assays compared to controls. Moreover, the activity of Src kinases, along with oxidative stress, were significantly diminished in Tg-C73A brains. Together, these data demonstrate that oxidation of KCNB1 channels is a contributing mechanism to cellular and behavioral deficits in vertebrates and suggest a new therapeutic approach to TBI.

Key words: aging; dasatinib; Kv2.1; oxidative stress; ROS; Src kinases

\section{Significance Statement}

This study provides the first experimental evidence that oxidation of a $\mathrm{K}^{+}$channel constitutes a mechanism of neuronal and cognitive impairment in vertebrates. Specifically, the interaction of KCNB1 channels with reactive oxygen species plays a major role in the etiology of mouse model of traumatic brain injury (TBI), a condition associated with extensive oxidative stress. In addition, a Food and Drug Administration-approved drug ameliorates the outcome of TBI in mouse, by directly impinging on the toxic pathway activated in response to oxidation of the KCNB1 channel. These findings elucidate a basic mechanism of neurotoxicity in vertebrates and might lead to a new therapeutic approach to TBI in humans, which, despite significant efforts, is a condition that remains without effective pharmacological treatments.

\section{Introduction}

Ion channels are versatile proteins that generate and modulate electricity across biological membranes. Since electricity is an

\footnotetext{
Received July 13, 2016; revised Aug. 25, 2016; accepted Sept. 7, 2016.

Author contributions: J.A., S.T.-V., and F.S. designed research; W.Y., R.P., S.T., M.G., Y.S., and F.S. performed research; W.Y., R.P., and F.S. analyzed data; F.S. wrote the paper.

This work was supported by National Science Foundation Grant 1456675 and NHH Grant 1R21NS096619-01 to F.S. The thy1.2 cassette was a kind gift from Dr. Pico Caroni. We thank Drs. Madura and Chen for help with the Zeiss Axio Imager and Shuang Liu for critical reading of this manuscript. We thank Nick Scurato for helping with the genotyping.

The authors declare no competing financial interests.

Correspondence should be addressed to Dr. Federico Sesti, Department of Neuroscience and Cell Biology, Rutgers University, Robert Wood Johnson Medical School, 683 Hoes Lane West, Piscataway, NJ 08854. E-mail: federico.sesti@rutgers.edu.

DOI:10.1523/JNEUROSCI.2273-16.2016

Copyright $\odot 2016$ the authors $\quad 0270-6474 / 16 / 3611084-13 \$ 15.00 / 0$
}

essential ingredient of life, ion channels are found in all organisms, from prokaryotes to eukaryotes to archaeans, in virtually any type of cell (Hille, 2001). A growing number of ion channels, including the potassium $\left(\mathrm{K}^{+}\right)$channels, are reported to interact with reactive oxygen species (ROS), either in cell signaling mechanisms or as a side effect of aging and disease (Patel and Sesti, 2016). Hence, oxidative modification of $\mathrm{K}^{+}$channels has the potential to constitute a widespread mechanism of vulnerability but a strong causative link between these modifications and behavioral and functional impairment has still to be established for vertebrates. One channel known to undergo oxidation is the delayed rectifier voltage-gated $\mathrm{K}^{+}$channel KCNB1 (Kv2.1), which carries a major somatodendritic current that regulates highfrequency firing of neurons in the cortex and hippocampus $(\mathrm{Mu}-$ 


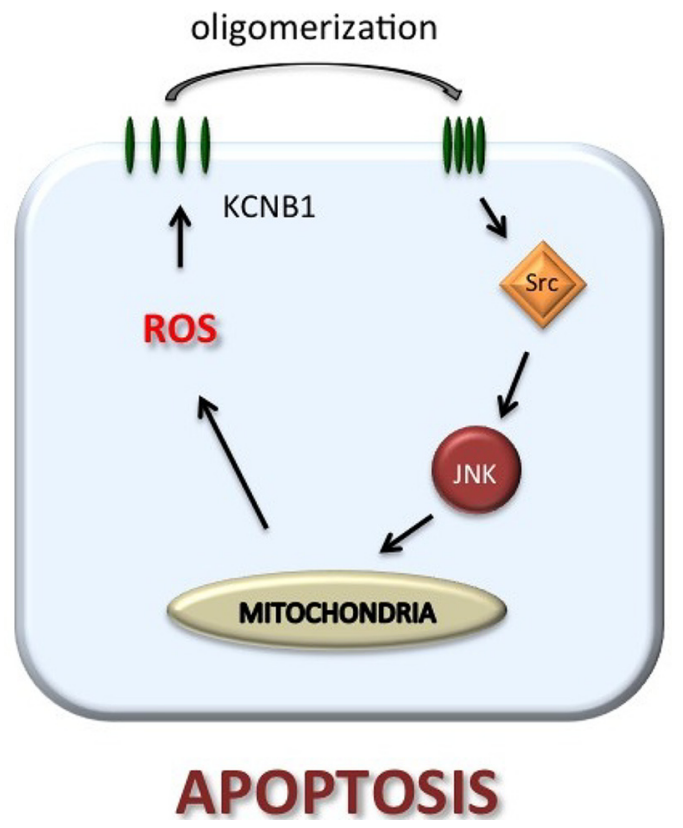

Figure 1. Predicted model of KCNB1-oxidation-mediated apoptosis. Oxidative stress induces the formation of KCNB1 oligomers that accumulate in the plasma membrane. The presence of these protein aggregates leads to the activation of Src and downstream JNK kinases. The latter act to destabilize mitochondria, resulting in the release of more ROS (which may further sustain KCNB1 oligomerization in a sort of auto-catalytic process) and apoptosis.

rakoshi and Trimmer, 1999; Du et al., 2000; Cotella et al., 2012). In vitro studies showed that oxidants cross-link KCNB1 subunits, giving rise to oligomers that do not conduct current. In addition, oxidized KCNB1 channels are poorly endocytosed and tend to build up in the plasma membrane (Wu et al., 2013). These KCNB1 protein aggregates favor the activation of Src tyrosine kinases and downstream Jun N-terminal kinases (JNK) that lead to apoptosis and release of more ROS by presumably destabilizing mitochondria (Fig. 1). KCNB1 oligomers have been detected in the brains of aged mice and, in larger quantities, in the brain of the $3 \mathrm{x}$-Tg-AD mouse model of Alzheimer's disease, which expresses abnormal amounts of ROS (Oddo et al., 2003; Smith et al., 2005; Sensi et al., 2008; Yao et al., 2009; Chou et al., 2011; McManus et al., 2011; Cotella et al., 2012). This body of evidence argues that oxidized KCNB1 channels may affect cortical and/or hippocampal excitability and, when oxidation is elevated, cause neuronal death. Indeed, Frazzini et al. (2016) showed recently that KCNB1 oligomers promote hyperexcitability in cultured $3 x T g-A D$ primary hippocampal neurons, but whether oxidized KCNB1 channels affect brain function is not known. To determine the role that oxidation of KCNB1 plays for the pathophysiology of the brain, we constructed a transgenic mouse that expresses a redox-resistant variant of human KCNB1 (C73A), which we showed previously does not oligomerize and thus conducts normally (Cotella et al., 2012). To expose the channels to controlled and reproducible conditions of oxidative stress, we subjected the animals to mild to moderate traumatic brain injury - which is associated with extensive oxidation during the secondary injury (Corps et al., 2015; Hiebert et al., 2015; Shen et al., 2016) — using the lateral fluid percussion (LFP) method (McIntosh et al., 1989; Alder et al., 2011; Roth et al., 2014). LFP produces both focal and diffuse brain injury and is associated with extensive axonal damage and cell death that result in longterm neuromotor and cognitive deficits (Smith et al., 1991; Miyazaki et al., 1992; Hamm et al., 1993; Hicks et al., 1993; Dixon et al., 1999). These deficits reflect the outcomes observed in human victims of TBI and the model has therefore been used extensively to identify potential therapeutic treatments (Thompson et al., 2005; Masel and DeWitt, 2010).

Here, we show that genetic suppression of KCNB1 oxidation is protective in TBI. Compared to nontransgenic mice or transgenic mice expressing the wild-type channel, $\mathrm{Tg}$-C73A animals exhibit significantly improved sensorimotor and learning and memory outcomes along with reduced inflammation, neurodegeneration, and cell death. Moreover, pharmacological impingement on the pathway activated by KCNB1 oxidation recapitulates the effects of decreasing KCNB1 oxidation by genetic means. Thus, specific Src tyrosine kinase inhibitor dasatinib, a Food and Drug Administration (FDA)-approved drug sold under the commercial name of Sprycel, currently used to treat certain forms of leukemia, ameliorates inflammation, neurodegeneration, and neuronal death and improves behavioral deficiency following the LFP injury.

\section{Materials and Methods}

Construction of $\mathrm{Tg}-\mathrm{WT}$ and $\mathrm{Tg}-\mathrm{C} 73 \mathrm{~A}$ transgenic mice. Transgenic mice were constructed by the Genome Editing Core Facility at Rutgers using pronuclear injection. cDNA encoding human KCNB1 tagged to the human influenza hemagglutinin (HA) tag in the C terminus (Cotella et al., 2012) was inserted in the mouse Thyl.2 cassette using a XhoI restriction site. Constructs were linearized at an EcoR V site, for injection. We obtained $3 \mathrm{Tg}$-WT and $4 \mathrm{Tg}$-C73A founders.

Biochemistry. The detailed biochemical procedure was described previously (Cotella et al., 2012). Briefly, frozen, half sagittal brains of either sex were homogenized with a glass tissue grinder in lysis buffer $(0.32 \mathrm{M}$ sucrose, 5 mm Tris-Cl pH 6.8, 0.5 mм EDTA, 1 mm PMSF, and protease inhibitor cocktail set I, Calbiochem). Samples were centrifuged at 2000 rpm for $10 \mathrm{~min}$, and the supernatant used for biochemical analysis. Protein content was quantified with the Bradford colorimetric assay (Sigma) and dissolved in Laemmli buffer with or without reducing agents. Proteins were resolved by $8 \%$ SDS-PAGE and transferred to a PVDF membrane that was incubated in a $5 \%$ solution of nonfat milk in Tween 20-PBS (PBST) for $2 \mathrm{~h}$ at room temperature. After overnight incubation at $4^{\circ} \mathrm{C}$ with the primary antibody (anti-Kv2.1 NeuroMab clone K89/34, UC Davis/NIH; anti-HA H6908, Sigma; anti-actin MAB1501, Millipore), the membrane was washed for $20 \mathrm{~min}$ and incubated at room temperature with the appropriate secondary antibody. To detect activated Src tyrosine kinases, brain lysates were incubated at $4^{\circ} \mathrm{C}$ overnight in the presence of anti-Src antibody (catalog \#2108, Cell Signaling Technology). Then, protein A agarose beads ( $30 \mu \mathrm{l}$ of $50 \%$ bead slurry) were added and incubated for $2 \mathrm{~h}$ at $4^{\circ} \mathrm{C}$. Samples were centrifuged for $30 \mathrm{~s}$ at $4^{\circ} \mathrm{C}$, and the pellet was washed five times in cell lysis buffer. The pellet was resuspended with $50 \mu \mathrm{l} 2 \times$ SDS Laemmli buffer, heated at $100^{\circ} \mathrm{C}$ for 10 $\mathrm{min}$, and centrifuged for $1 \mathrm{~min}$ at $14,000 \times \mathrm{g}$. The sample was loaded on $8 \%$ SDS-PAGE gel and immunoblotted with either anti-Src antibody or anti-P-Src-antibody (catalog \#2101, Cell Signaling Technology). The blots were washed in PBST for $20 \mathrm{~min}$ and incubated for $5 \mathrm{~min}$ with chemiluminescence substrates and exposed. Densitometric analysis was performed using Image $(\mathrm{NIH})$ software.

Lateral fluid percussion injury. All experimental protocols involving animals were approved by the Rutgers University Institutional Animal Care and Use Committee. LFP brain injury involves the displacement of neural tissue by a rapid fluid pulse to the brain and has been described in detail previously (Alder et al., 2011). For surgery, 3-month-old males were anesthetized with $4-5 \%$ isoflurane in $100 \% \mathrm{O}_{2}$ and placed in a mouse stereotaxic frame. Mice were maintained at $2 \%$ isoflurane, and respiration was monitored throughout the procedure. The site of injury was located halfway between lambda and bregma, and between the sagittal suture and the lateral ridge over the right hemisphere. A $3 \mathrm{~mm}$ thin plastic disc was fixed with Loctite glue (444 Tak Pak, Henkel) onto the skull. Using a trephine ( $3 \mathrm{~mm}$ outer diameter), a craniotomy was performed, keeping the dura intact. A rigid Luer lock needle hub $(3 \mathrm{~mm}$ 
inside diameter) was secured to the skull over the opening with cyanoacrylate adhesive and dental acrylic (Butler Schein). The skull sutures were sealed with the cyanoacrylate to ensure that the fluid bolus from the injury remained within cranial cavity and the hub was filled with saline. After a $60 \mathrm{~min}$ period of recovery, the animals were reanesthetized and connected to the fluid percussion injury device (Custom Design and Fabrication, Virginia Commonwealth University) through the Luer-loc fitting of the hub. Once a normal breathing pattern resumed, before sensitivity to stimulation, a $\sim 1.5$ atm pulse $(\sim 15 \mathrm{~ms})$ was generated through the LFP device. Upon return of the righting reflex (4-10 min for moderate injury), the hub and dental acrylic were removed. The scalp incision was sealed with $3 \mathrm{M}$ Vetbond (Thermo Fisher Scientific) and the animals were returned to normal housing conditions. At this moderate level of injury, $\sim 10 \%$ of animals died as a result of the injury within the acute posttraumatic period ( $15 \mathrm{~min})$, generally from respiratory failure and pulmonary edema (Lifshitz, 2008). This is a normal and anticipated feature of the TBI model because it mimics human TBI (Domeniconi et al., 2007). Mice that undergo the surgical procedures but that were uninjured served as the sham controls. Assignment of mice to the LFP or sham group was done in a random manner.

Drug administration. Dasatinib (LC Laboratories) was given intraperitoneally at $25 \mathrm{mg} / \mathrm{kg}$. Dasatinib was diluted in vehicle solution ( $50 \mathrm{~mm} \mathrm{NaAc}, \mathrm{pH}$ 5.0) from a $200 \mathrm{mg} / \mathrm{ml}$ stock in dimethyl sulfate. Each mouse was subjected to a daily dose of either vehicle or dasatinib solution via an intraperitoneal injection starting from the day of surgery ( $2 \mathrm{~h}$ after injury).

Behavioral assays. For the Morris water maze (MWM), mice were acclimated to the paradigm and tested for baseline response using a visible platform test $4 \mathrm{~d}$ before injury. The animals were placed in a circular pool of water containing nontoxic white paint and a clear platform for escape. To assess learning, mice were trained using a hidden platform fixed in one of four quadrants for 6 consecutive days starting at $2 \mathrm{~d}$ postinjury (dpi; four trials/day). Black and white distal cues were placed on the walls. The quadrant in which the mouse was placed was pseudorandomly varied throughout training, and the time to locate the platform was recorded. Maximum trial time was $60 \mathrm{~s}$, and the mouse remained or was placed on the platform for $15 \mathrm{~s}$ and warmed for $10 \mathrm{~min}$ between trials. To assess memory retention, the day after the last training session ( $8 \mathrm{dpi})$, the animals were subjected to a $60 \mathrm{~s}$ probe trial with the platform removed and the time spent in the target quadrant was measured (Longhi et al., 2005). Data were recorded using a video-tracking system (EthoVision XT, Noldus Information Technology).

Vestibulomotor rotarod test. A separate set of mice was used for motor testing. Mice were acclimated to the rotarod device three times per day with $1 \mathrm{~h}$ intertrial intervals for the $2 \mathrm{~d}$ before the surgery. Balance and motor function were measured on a $36 \mathrm{~mm}$ outer diameter rotating rod whose velocity increased from 4 to $40 \mathrm{rpm}$ over a maximum $180 \mathrm{~s}$ interval. Each trial ended when the animal fell off the rotarod. At 1, 7, and 21 dpi, each subject underwent three trials a day with $1 \mathrm{~h}$ intertrial intervals on the rotarod device. The same mice were used for each time point. The average latency to fall of injured mice was recorded and was compared to that of sham mice.

Immunohistochemistry. Mice were perfused transcardially with $0.9 \%$ saline followed by $4 \%$ paraformaldehyde at either 7, 14 and $21 \mathrm{dpi}$. The brains were cryoprotected in $30 \%$ sucrose, and $20 \mu \mathrm{m}$ frozen sections were prepared throughout the site of injury on the cortex and the hippocampus in a 1:20 series so that the same set of tissue samples could be used for expression of different makers. For activated Caspase-3,
KCNB1, and HA immunohistochemistry, sections were pretreated with $0.01 \mathrm{M}$ citrate buffer, and then anticleaved Caspase- 3 antibody (1:1000, catalog \#9661, Cell Signaling Technology) or anti-KCNB1 antibody (1: $100)$ or anti-HA antibody $(8 \mu \mathrm{g} / \mathrm{ml})$ was applied overnight, followed by application of the appropriate secondary conjugated antibody. For Fluoro-Jade C (FLJC) staining, sections were pretreated with $1 \% \mathrm{NaOH}$ and $0.06 \% \mathrm{KMnO} 4$, and then $0.0005 \%$ Fluoro-Jade C (catalog \#AG325, Millipore) $/ 0.0001 \%$ was applied for $10 \mathrm{~min}$. For glial fibrillary acidic protein (GFAP), slides were incubated overnight with anti-GFAP antibody at $4^{\circ} \mathrm{C}(1: 500$, catalog \#MAB3402, Millipore). Slides were then incubated in $2^{\circ}$ goat anti-mouse antibody (1:500, Alexa Fluor 594). All slides were mounted in Vectashield Antifade Mounting Medium with DAPI mounting buffer (Vector Laboratories) and stored at $4^{\circ} \mathrm{C}$. Staining was visualized on a Zeiss Axiophot microscope at $40 \times$ or with a Zeiss Axio Imager M1 at $100 \times$ (images in Fig. 2C). Positive cells on the ipsilateral hemisphere were counted in coronal sections representing a 1:20 series throughout the site of injury at the cortex and inclusive of the entire length of the hippocampus. For the cortex, a total of six fields of view at $40 \times$ (three most dorsal along the surface of the cortex starting from midline and moving laterally and three just ventral to those fields) were counted on the side ipsilateral to the injury. The ipsilateral hippocampus including CA1 and CA3 as well as the dentate gyrus was used for quantitation of cells in the hippocampus.

Preparation of hippocampal neuronal cultures. The detailed procedure was described previously (Thakker-Varia et al., 2001). Briefly, hippocampi were obtained from time-mated embryonic day 16 (E16) mice killed by $\mathrm{CO}_{2}$ asphyxiation. Hippocampal tissue from individual embryos was mechanically triturated in Neurobasal medium containing B27 (Invitrogen) and glutamine and plated in two $35 \mathrm{~mm}$ poly-D-lysinecoated Petri dishes at $\sim 350,000$ cells/dish ( $1.5 \mathrm{ml} \mathrm{medium} / \mathrm{dish})$. Cultures were maintained in Neurobasal medium at $37^{\circ} \mathrm{C}$ in a $95 \%$ air $/ 5 \%$ $\mathrm{CO}_{2}$ humidified incubator and contained virtually pure neurons. Tail samples from individual embryos were processed for genotyping.

Electrophysiology. Data were recorded with an Axopatch 200B amplifier (Molecular Devices), a personal computer (Dell), and Clampex soft- 
A anti-KCNB1
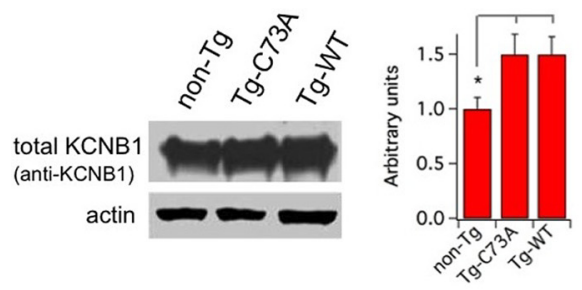

C

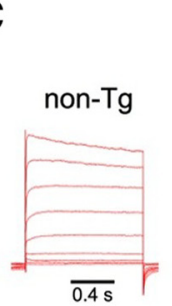

\section{Tg-WT}

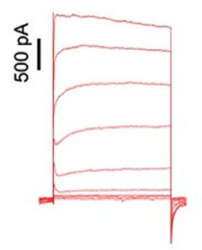

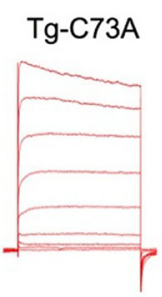

B

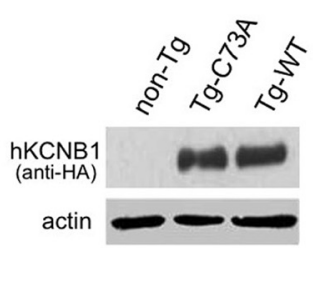

D

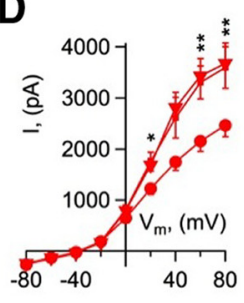

Figure 3. Hippocampal neurons from transgenic embryos exhibit increased outward $\mathrm{K}^{+}$current. $\boldsymbol{A}$, Representative Western blot and densitometric analysis from brain lysates stained with anti-KCNB1 (data normalized to non-Tg). $p=0.015$ with pairwise comparisons all statistically significant except Tg-WT versus Tg-C73A (one-way ANOVA/Tukey's post hoc test). $N=4$ experiments. $\boldsymbol{B}$, Representative Western blot and densitometric analysis of brain lysates stained with anti-HA (data normalized to Tg-WT). Differences between Tg-WT and Tg-C73A means are not statistically significant (two-tailed Student's ttest). $N=3$ experiments. $C$, Representative whole-cell currents elicited in non- $\mathrm{Tg}$, $\mathrm{Tg}-\mathrm{WT}$, and Tg-C73A hippocampal neurons by voltage jumps from -80 to $+80 \mathrm{mV}$ in $20 \mathrm{mV}$ increments. The holding voltage is $-80 \mathrm{mV}$. D, Mean steady-state current-voltage relationships for non- $\mathrm{Tg}$ (circles), Tg-WT (squares), and Tg-C73A (triangles). Data are from $n=15$ (non- Tg), $n=18$ (Tg-WT), and $n=16$ (Tg-C73S) neurons. $p \leq 0.019$ for longitudinal statistical comparisons at $+20,+60$, and $+80 \mathrm{mV}$ (one-way ANOVA). Pairwise comparisons at $+20,+60$, and $+80 \mathrm{mV}$ are all statistically significant except Tg-WT versus Tg-C73A (Tukey's post hoc test). $\boldsymbol{E}$, Normalized macroscopic conductance-voltage relationships (Eq. 1) for non-Tg (circles, $n=15$ ), Tg-WT (squares, $n=18$ ), and Tg-C73A (triangles, $n=16$ ). Data were fitted to the Boltzmann function (Eq. 2, solid lines) with $V_{1 / 2}=2.1,9.3$, and $5.4 \mathrm{mV}$ for non- $\mathrm{Tg}$, Tg-WT, and Tg-C73A, respectively. ${ }^{*} p<0.05 ;{ }^{* *} p<0.01$.

ware (Molecular Devices). Data were filtered at $f_{\mathrm{c}}=1 \mathrm{kHz}$ and sampled at $2.5 \mathrm{kHz}$. The bath solution contained the following (in $\mathrm{mM}$ ): $5 \mathrm{KCl} ; 100$ $\mathrm{NaCl}$; 10 HEPES, pH 7.5 with $\mathrm{NaOH} ; 1.8 \mathrm{CaCl}_{2} ; 1.0 \mathrm{MgCl}_{2}$; and 10 D-glucose. The pipette solution contained the following (in $\mathrm{mm}$ ): $100 \mathrm{KCl} ; 10$ HEPES, pH 7.5 with KOH; 10 EGTA, pH 7.5 with $\mathrm{KOH} ; 1.0$ $\mathrm{MgCl}_{2}$; and $1.0 \mathrm{CaCl}_{2}$. Offset potentials due to series resistances $(\leq 5 \mathrm{mV})$ were not compensated for when generating current-voltage relationships. Macroscopic conductances were calculated as follows:

$$
G(V)=\frac{I}{V-V_{\text {rev }}},
$$

where $I$ is the steady-state current, $V$ is the applied voltage, and $V_{\text {rev }}$ is the computed Nernst potential for $\mathrm{K}^{+}$at the experimental concentrations used $(-103 \mathrm{mV})$. Macroscopic conductances were fitted to the Boltzmann function:

$$
G(V)=G_{\max }=\frac{1}{1+e^{\left(V_{1 / 2}-V\right) / V_{s}}}
$$

where $V_{1 / 2}$ is the voltage at which $G / G_{\text {Max }}=1 / 2$, and $V_{\mathrm{s}}$ is the slope factor.

Apoptosis assays. The neurons were washed with PBS and exposed to $50 \mu \mathrm{M} 2,2^{\prime}$-dithiodipyridine (DTDP; Sigma) for $5 \mathrm{~min}$. The cells were washed two times with PBS and incubated for $6 \mathrm{~h}$ in fresh medium. Then, the cells were washed with PBS and incubated for 15 min with Annexin-V labeling buffer solution according to the kit's instructions (Annexin-VFLUOS staining kit, Sigma). We showed previously that C73A truly acts to inhibit apoptosis rather than just delay it (Cotella et al., 2012). Cells were mounted on a Leica DMIRB inverted microscope equipped with a digital camera and photographed (six to eight images per culture) for subsequent analysis. Experiments were performed blind. The fluorescence of Annexin-V in each image was calculated using ImageJ software.
anti-HA

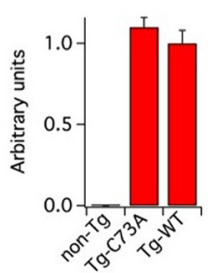

E

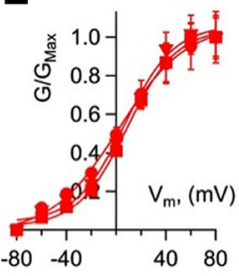

Statistical analysis. Quantitative data are presented as mean \pm SEM. The level of significance, assumed at the $95 \%$ confidence limit or greater $(p<0.05)$, was calculated using Student's $t$-test (http://studentsttest.com) and one-way ANOVA with a Tukey's post hoc test (http://astatsa.com/OneWay_Anova_with-

_TukeyHSD). For ANOVA tests with (1) more than three independent samples or (2) comparisons between samples from different groups of data ("longitudinal"), only the $p$ value is indicated in the figure, while the $p$ value and the statistical significance of pairwise comparisons are indicated in the legend $\left({ }^{*} p<0.05\right.$ and ${ }^{* *} p<0.01$ in all figures).

\section{Results \\ Construction of transgenic mice expressing human KCNB1}

To study oxidation of KCNB1 channels in vivo, we engineered two transgenic mice, expressing respectively, a nonoxidable variant of human KCNB1 (C73A) and the wild-type channel as a control, both tagged to the HA epitope tag in the $\mathrm{C}$ terminus in a B6XCBA background. We showed previously that the addition of the HA tag has no effect on oxidation or other properties of the channel (Cotella et al., 2012; Wu et al., 2013). We refer to these mice simply as Tg-C73A and Tg-WT. To direct expression of hKCNB1 mainly in cortex and hippocampus, we subcloned the channel in the thy1.2 cassette, which represents the standard for expression in these regions of the mouse brain (Aigner et al., 1995). Transgenic mice were constructed using pronuclear injection. We obtained 3 Tg-WT founders and $4 \mathrm{Tg}-\mathrm{C} 73 \mathrm{~A}$ founders. All transgenic animals heterozygous in hKCNB1 were normal in size and weight (32.4 $\pm 1.0,32.1 \pm 0.6$, and $32.6 \pm 1.5 \mathrm{~g}$, respectively, for 3-month-old non-Tg, Tg-WT, and Tg-C73A mice of either sex; $N=30$ mice/group) and did not exhibit any apparent phenotype. In contrast, while homozygous $\mathrm{Tg}$-C73A were normal, homozygous Tg-WT developed more slowly and exhibited high mortality rates after LFP injury (58 vs $12 \%$ of homozygous TgC73A). In what follows, we present results obtained with line \#54 (Tg-WT) and line \#18 (Tg-C73A), both heterozygous in hKCNB1 (mortality rates after LFP injury, 13 and 9\%, respectively).

\section{Transgenic KCNB1 channels are expressed in cortex and hippocampus}

To confirm that hKCNB1 was expressed in the cortex and hippocampus, coronal frozen sections cut from the brains of 3-month-old animals of either sex were fixed and stained with an antibody against the HA tag (anti-HA) that recognizes only transgenic hKCNB1 and, separately, with an antibody against KCNB1 (anti-KCNB1) that detects both mouse (mKCNB1) and human KCNB1 (hKCNB1) through a conserved C-terminal epitope (HMLPGGGAHGSTRDQSI). As expected, hKCNB1 was detected only in the cortex and hippocampus of transgenic sections, whereas total KCNB1 was detected also in nontransgenic sections (Fig. 2A). Furthermore, we did not detect appreciable KCNB1 
expression in other areas of the brain. Staining with either KCNB1 or HA antibody revealed typical cluster distribution of KCNB1 channels in the plasma membrane of both cortical (Fig. $2 B$ ) and hippocampal neurons (Fig. 2C; Rhodes et al., 1995; Lim et al., 2000; O'Connell et al., 2006, 2010; Sarmiere et al., 2008; Fox et al., 2013).

Transgenic hKCNB1 channels contribute to outward $\mathrm{K}^{+}$current in hippocampal neurons

To assess the relative amounts of endogenous and transgenic KCNB1 protein and consequently to have a rough measure of the level of overexpression of the latter, half brains were lysed, immunoblotted, and analyzed by densitometry. Results of four experiments with the anti-KCNB1 antibody indicated that the amounts of transgenic channels were comparable in the two transgenic lines and were about half the amounts of endogenous channels (Fig. 3A). When similar experiments were performed with the anti-HA antibody, hKCNB1 was not detected in non-Tg brains, as expected, and its levels were similar in the two transgenic lines, in agreement with the results of the experiments with anti-KCNB1 (Fig. 3B). To assess the contribution of transgenic KCNB1 channels to total neuronal current, we recorded somatic whole-cell currents in primary hippocampal neurons obtained from nontransgenic and transgenic embryos. Voltage jumps ranging from -80 to $+80 \mathrm{mV}$ (from an holding voltage of $-80 \mathrm{mV}$ ) evoked robust outward currents that reversed around $-40 \mathrm{mV}$ (Fig. 3C,D; data are shown without subtraction of leak currents). Steady-state current amplitudes at $+80 \mathrm{mV}$ were comparable in $\mathrm{Tg}-\mathrm{WT}$ and $\mathrm{Tg}-\mathrm{C} 73 \mathrm{~A}$ transgenic neurons and were roughly $\sim 40 \%$ larger than in non- Tg neurons, consistent with biochemical results (Fig. $3 A$ ) and with previous studies that showed that C73A KCNB1 channels conduct like WT KCNB1 channels (Cotella et al., 2012). Normalized macroscopic conductances (Fig. $3 E$ ) fitted to a Boltzmann function exhibited half-activation $\left(V_{1 / 2}\right)$ values around $0 \mathrm{mV}$ in good agreement with the results of others (Frazzini et al., 2016). The $V_{1 / 2}$ values of transgenic conductances were slightly more positive than those of nontransgenic conductances $\left(V_{1 / 2}=1.8 \pm 0.3,8.7 \pm 2.1\right.$, and $5.7 \pm 1.1$ $\mathrm{mV}$ for non-Tg, $\mathrm{Tg}-\mathrm{WT}$, and $\mathrm{Tg}-\mathrm{C} 73 \mathrm{~A}$, respectively), but these differences were not statistically significant.

Overall, these data indicate that the transgenic channels are expressed in neurons of the cortex and hippocampus and that the cys73 to ala replacement in KCNB1 does not affect the channels' functional attributes or their ability to cluster in the plasma membrane. We cannot rule out that the resolution of our analysis may have missed micro differences in cluster distributions of the transgenic channels. However, since clustering affects KCNB1 conduction (O'Connell et al., 2006, 2010; Fox et al., 2013), considering that there were no differences in total outward $\mathrm{K}^{+}$currents expressed in $\mathrm{Tg}-\mathrm{WT}$ and $\mathrm{Tg}-\mathrm{C} 73 \mathrm{~A}$ hippocampal neurons, this possibility seems unlikely.
B injured

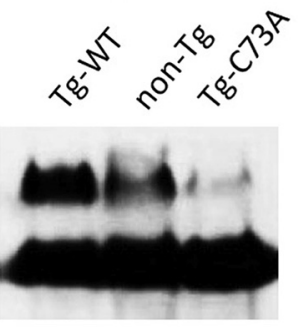

anti-KCNB1

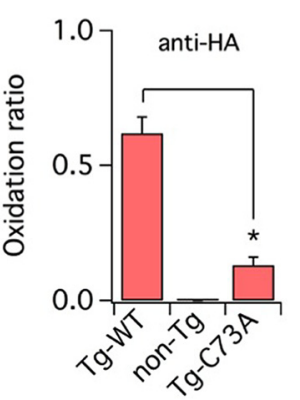

un-injured

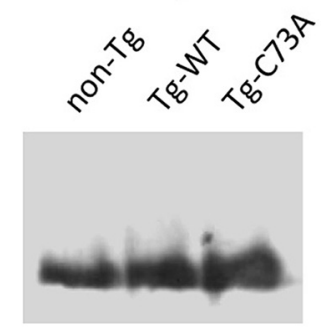

D anti-HA ( $\mathrm{CHO}$ cells)

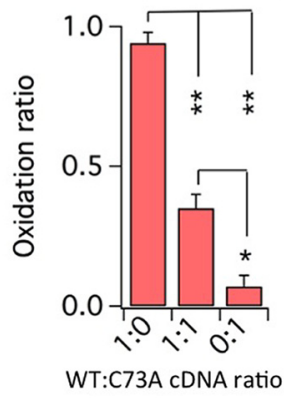

WT:C73A cDNA ratio
Figure 4. The level of KCNB1 oxidation is low in the Tg-C73A brain. $A$, Representative Western blots of total KCNB1 channels in the brains of injured non- $\mathrm{Tg}$ mice in the absence in the sample buffer of denaturants or reducing agents or in the presence of $1.0 \mathrm{mM}$ $\mathrm{H}_{2} \mathrm{O}_{2}$ or $20 \mathrm{~mm}$ reducing agent DTT. $\boldsymbol{B}$, Representative Western blots of total $K C$ NB1 channels in the injured (quantification in C) or (anti-HA, $N=3$ experiments). In experiments with anti-KCNB1, $p=0.005$, with pairwise comparisons all statistically ometry and detected with anti-HA. $p=0.00012$, with pairwise comparisons all statistically significant (one-way ANOVA/Tukey's post hoc test). $N=3$ experiments. ${ }^{*} p<0.05 ;{ }^{* *} p<0.01$.

\section{Oxidation of KCNB1 is negligible in Tg-C73A mice}

The LFP injury enabled us to expose live animals to conditions of oxidative stress in a reproducible fashion. However, this ap-
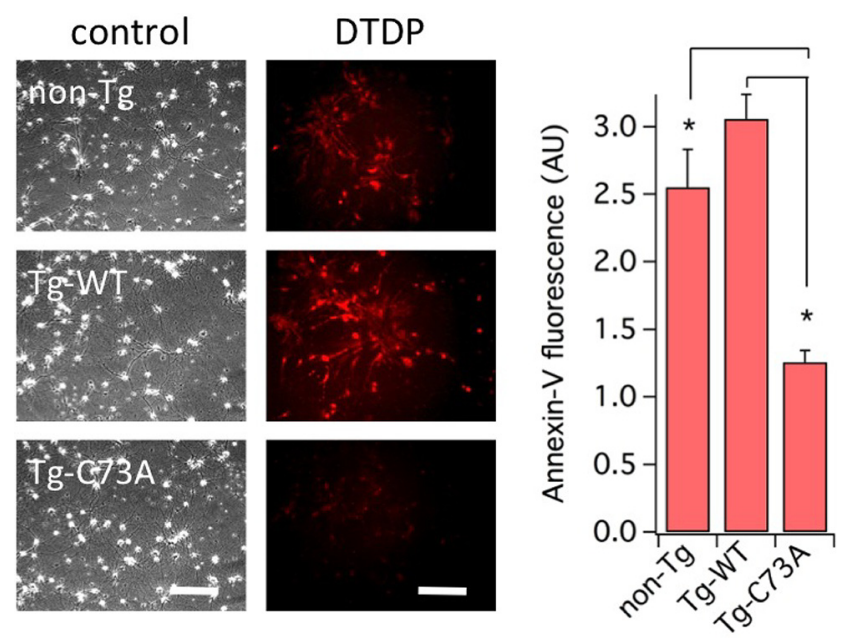

Figure 5. Tg-C73A hippocampal neurons are resistant to oxidant-induced apoptosis. Representative images of cultured primary hippocampal neurons of the indicated genotypes in control (no oxidant, bright light) or exposed to $50 \mu \mathrm{m}$ DTDP for 5 min and stained with Annexin-V $6 \mathrm{~h}$ after oxidation (fluorescent light). Quantitative assessment of Annexin-V fluorescence (proportional to the number of cells undergoing apoptosis, arbitrary units) $6 \mathrm{~h}$ after oxidation is shown on the right. Scale bars: $200 \mu \mathrm{m} . p<0.0001$, with pairwise comparisons all statistically significant except non-Tg versus Tg-WT (one-way ANOVA/Tukey's post hoc test). Neurons were obtained from $N=2$ non-Tg, $4 \mathrm{Tg}-\mathrm{WT}$, and $4 \mathrm{Tg}$-C73A embryos. * $p<0.05$. 

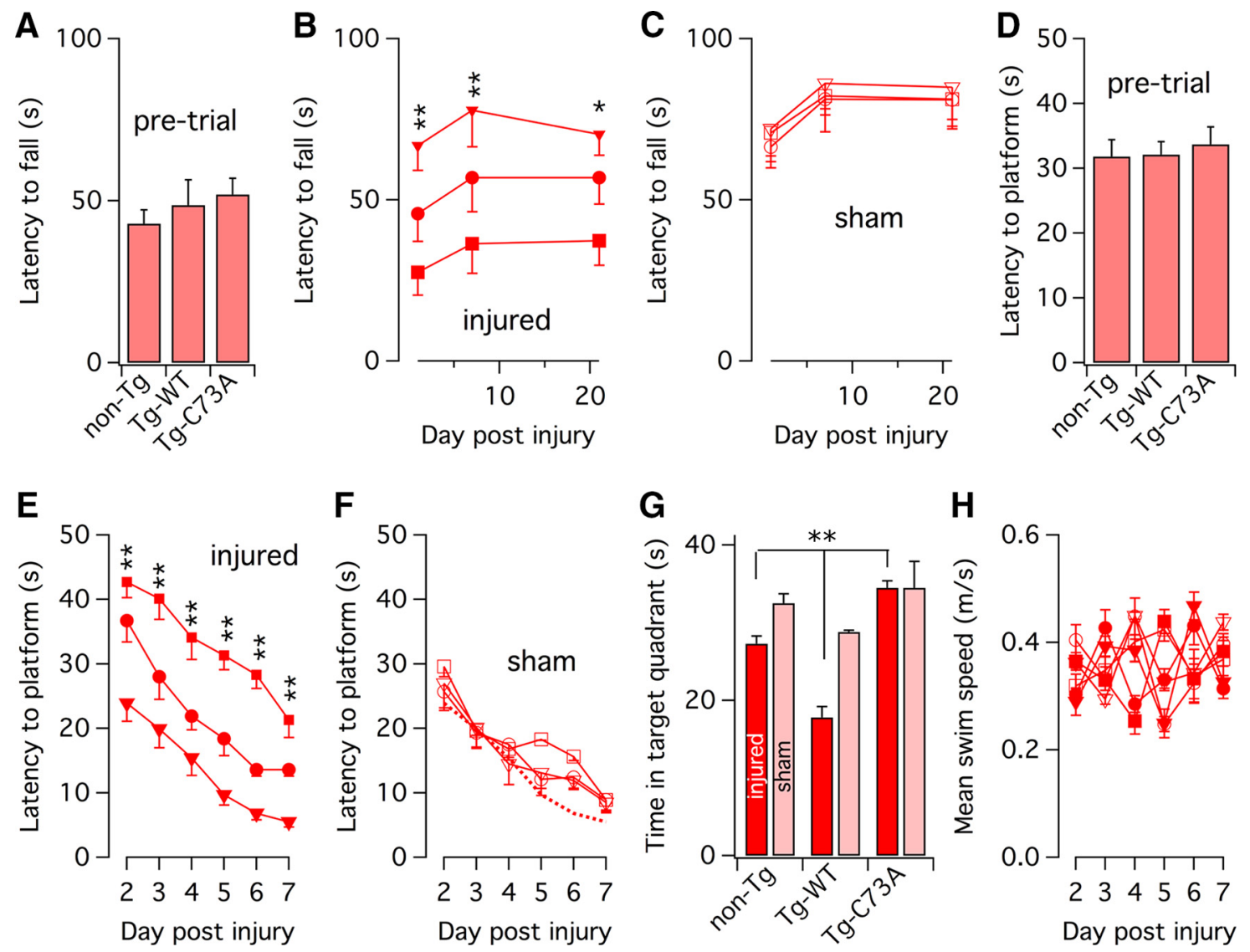

Figure 6. KCNB1 oxidation negatively affects behavioral outcome. $A$, Latency to fall from the rotating rod for the indicated groups of mice $2 \mathrm{~d}$ before surgery. Differences between means are not statistically significant (one-way ANOVA). $N=16,16$, and 16 for non- $\mathrm{Tg}$, Tg-WT, and Tg-C73A groups, respectively. $\boldsymbol{B}$, Latency to fall from the rotating rod for injured non-Tg (circles), $\mathrm{Tg}$-WT (squares), and Tg-C73A (triangles) mice. $p \leq 0.014$ for longitudinal statistical comparisons at each individual dpi (one-way ANOVA). Pairwise comparisons are all statistically significant except Tg-WT versus non-Tg at $1 \mathrm{dpi}$, Tg-WT versus non-Tg at $21 \mathrm{dpi}$, and non-Tg versus Tg-C73A at 21 dpi. (Tukey's post hoc test). In three experiments, $N=7,7$, and 8 mice, respectively, for non-Tg, Tg-WT, and Tg-C73A. C, Latency to fall from the rotating rod for non-Tg (circles), Tg-WT (squares), and Tg-C73A (triangles) shams. Differences between means are not statistically significant (one-way ANOVA). In three experiments, $N=7,7$, and 8 mice, respectively, for non-Tg, Tg-WT, and Tg-C73A. D, Latency to reach the platform of the indicated genotypes $4 \mathrm{~d}$ before surgery. Differences between means are not statistically significant (one-way ANOVA). $N=21,19$, and 17, respectively, for non-Tg, Tg-WT, and Tg-C73A mice. E, Latency to reach the platform of injured non- $\mathrm{Tg}$ (circles), Tg-WT (squares), and Tg-C73A (triangles) mice. $p \leq 0.0007$ for longitudinal statistical comparisons at each individual dpi (one-way ANOVA). Pairwise comparisons are all statistically significant except Tg-WT versus non-Tg at $2 \mathrm{dpi}$, non-Tg versus Tg-C73A at $3 \mathrm{dpi}$, and non-Tg versus Tg-C73A at 4 dpi (Tukey's post hoc test). In six experiments, N $=12,10$, and 9 mice, respectively, for non- $\mathrm{Tg}$, $\mathrm{Tg}-\mathrm{WT}$, and Tg-C73A. F, Latency to reach the platform of non- $\mathrm{Tg}$ (circles), $\mathrm{Tg}-\mathrm{WT}$ (squares), and Tg-C73A (triangles) shams. The response of injured Tg-C73A mice (dotted line) is shown for comparison. Differences between means are not statistically significant (one-way ANOVA). In six experiments, N=7, 7, and 7 mice, respectively, for non- $\mathrm{Tg}$, Tg-WT, and Tg-C $73 \mathrm{~A}$. $G$, Consolidated memory retention test for the indicated groups of mice. For LFP-injured mice, $p=0.0001$, with pairwise comparisons all statistically significant (one-way ANOVA/Tukey's post hoc test). For sham mice, differences between means are not statistically significant (one-way ANOVA). In six experiments, $N=12,10$, and 9 mice, respectively, for non-Tg, Tg-WT, and Tg-C73A, and $N=7,7$, and 7 mice for their respective shams. $\boldsymbol{H}$, Mean swimming speeds of injured and sham mice. Symbols are as in the other panels. Differences between means are not statistically significant (one-way ANOVA). Speeds were calculated using EthoVision XT software. In six experiments, $N=12,10$, and 9 mice, respectively, for non- $\mathrm{Tg}$, $\mathrm{Tg}$-WT, and $\mathrm{Tg}-\mathrm{C} 73 \mathrm{~A}$, and $N=7,7$, and 7 mice for their respective shams. ${ }^{*} p<0.05 ;{ }^{* *} p<0.01$.

proach was valid only if KCNB1 oxidation remained low in the injured Tg-C73A brain. To answer this crucial question we assessed the extent of KCNB1 oxidation in the brains of the various genotypes using Western blot analysis as done previously (Cotella et al., 2012). Oxidized KCNB1 channels in the mouse brain or heterologously expressed in mammalian cells form oligomers held together by disulfide bridges that run with multiple molecular masses ranging from 170 to $500 \mathrm{kDa}$ and that are suppressed by reducing agents DTT and $\beta$-mercaptoethanol (Cotella et al., 2012). Indeed, a fraction of total KCNB1 channels from lysates of injured non-Tg brains were run as oligomers with a molecular mass of $\sim 200 \mathrm{kDa}$ in the absence of reducing or denaturing agents (Fig. 4A). This fraction of oligomers was enriched by $\sim 40 \%$ following exposure to $1.0 \mathrm{~mm}$ hydrogen peroxide $\left(\mathrm{H}_{2} \mathrm{O}_{2}\right)$ and was abolished by $20 \mathrm{~mm}$ DTT. KCNB1 oligomers were present in lysates of injured Tg-WT and non-Tg brains and in very low amounts in $\mathrm{Tg}$-C73A lysates, but not in uninjured brains
(Fig. 4A). Densitometric analysis indicated that the ratio between the oligomeric and monomeric bands (oxidation ratio; Cotella et al., 2012), which gives a measure of the level of KCNB1 oxidation, was moderately increased in Tg-WT mice compared to non- $\mathrm{Tg}$ mice (35\% increase; Fig. $4 C$ ), and most importantly, this ratio was significantly decreased in the brains of Tg-C73A compared to non-Tg mice (70\% decrease). Similar oxidation ratios were obtained using the anti-HA antibody, except that no protein was detected in lysates of non-Tg brains, as expected (Fig. 4C). The low level of KCNB1 oxidation in the Tg-C73A brain could be due to the formation of heteromeric channels composed of endogenous and transgenic subunits, as the mouse and human channel share 97\% amino acid sequence identity (CLUSTALW alignment, https://npsa-prabi.ibcp.fr/cgi-bin/npsa_automat. pl?page $=/$ NPSA/npsa_clustalw.html). To test this idea, we expressed WT/C73A heterometric channels in Chinese hamster ovary cells and oxidized them with $1.0 \mathrm{~mm}$ hydrogen peroxide 
as done previously (Cotella et al., 2012). In cells transfected with an equal ratio of wild-type and C73A cDNA, the oxidation ratio was roughly one-third that of cells expressing the wild-type channel alone (Fig. 4D), a fraction comparable to that detected in injured $\mathrm{Tg}-\mathrm{C} 73 \mathrm{~A}$ brains. The lack of oligomerization prevents $\mathrm{C} 73 \mathrm{~A}$ mutant channels heterologously expressed in mammalian cells to induce apoptosis in response to an oxidative challenge (Wu et al., 2013). Since KCNB1 oligomerization was low in TgC73A brains, their neurons should be resistant to oxidant-induced apoptosis. Therefore, we challenged cultures of primary hippocampal neurons with DTDP, a potent oxidant, and assessed apoptosis. Representative pictures of cells in control or oxidized and stained with apoptotic marker Annexin-V are shown in Figure 5. Thus, in agreement with previous studies (Redman et al., 2007), non-Tg neurons were susceptible to DTDP-induced apoptosis. However, while Tg-WT neurons exhibited levels of apoptosis comparable to those of non-Tg cells, Tg-C73A neurons were significantly less susceptible. Together, these data indicated that oxidation of KCNB1 and the toxic effects associated with it are low in the brains of TgC73A mice.

Tg-C73A mice perform better than non-Tg and Tg-WT mice on the rotarod To determine the impact of KCNB1 channel oxidation on the function of the brain, we tested the animals on the accelerating rotarod device (rotarod) and the MWM, which respectively provide sensitive measures of the function of the motor and sensory cortex and the hippocampus (Smith et al., 1995; Laurer and McIntosh, 1999), the areas of the brain most affected by the injury in our LFP model (the injury occurs at the motor and sensory cortex, which is overlying the hippocampus; Alder et al., 2011). Two days before undergoing surgery, the mice were exposed to the rotarod paradigm. This procedure served the double purpose of allowing the animals to acclimatize to the new protocol and allowing us to identify impaired animals or detect differences due to genotype and normalize data to baseline response.

However, all mice behaved similarly during pretesting before injury, indicating that genotype did not affect baseline motor function (Fig. 6A). In contrast, mice subjected to the LFP injury had a shorter latency to fall relative to their shams, and most importantly, Tg-C73A injured mice could remain longer on the rotating cylinder than Tg-WT or non-Tg mice (Fig. $6 B$ ). There were no significant differences between the latencies of the shams (Fig. $6 C)$, strengthening the notion that in the absence of events that
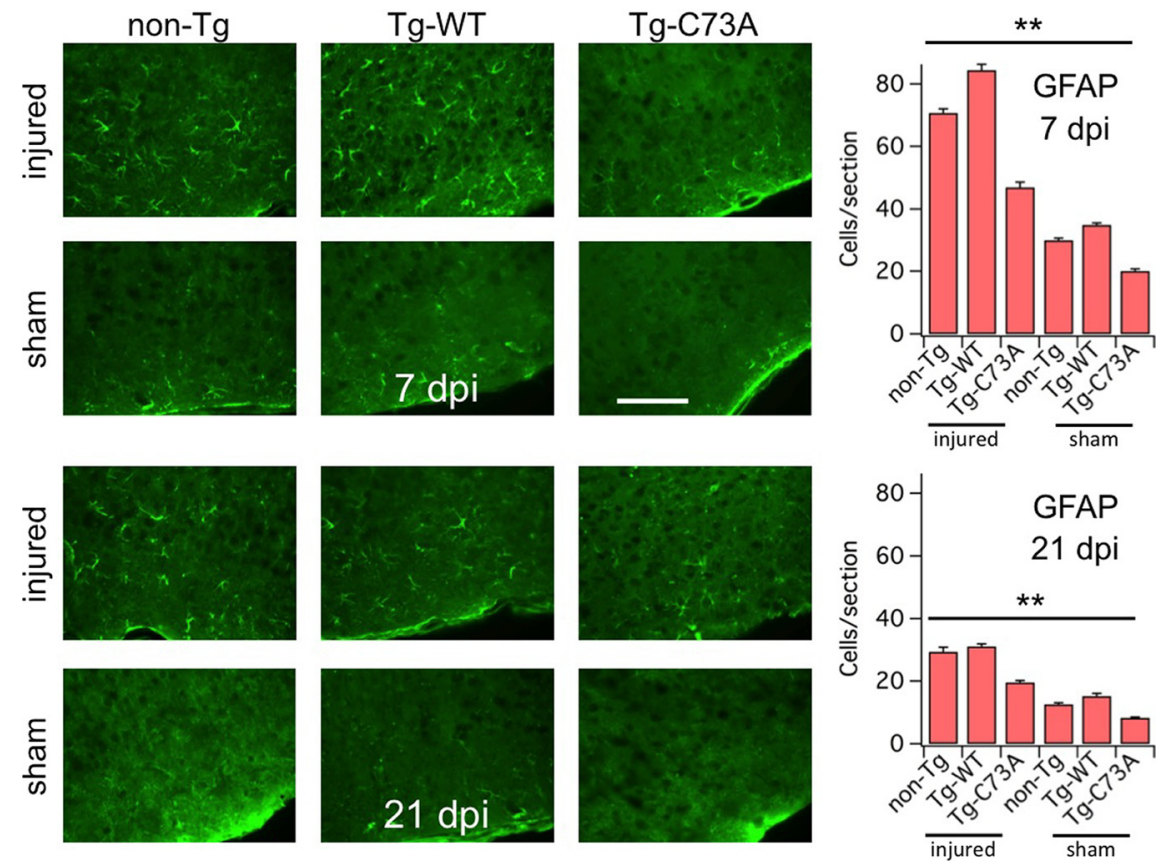

Figure 7. Inflammation is decreased in the cortex of Tg-C73A mice following the LFP injury. Representative images of coronal cortical sections from the brains of the indicated genotypes stained with GFAP antibody and the mean number of cells positive for GFAP per section at the indicated dpi. Scale bar, $200 \mu \mathrm{m}$. At both 7 and $21 \mathrm{dpi}, p<0.0001$, with pairwise comparisons all statistically significant except sham non-Tg versus sham Tg-WT (one-way ANOVA/Tukey's post hoc test). Each single mean was calculated from 18 sections from 3 brains ( 6 fields of view/section). ${ }^{* *} p<0.01$.
A

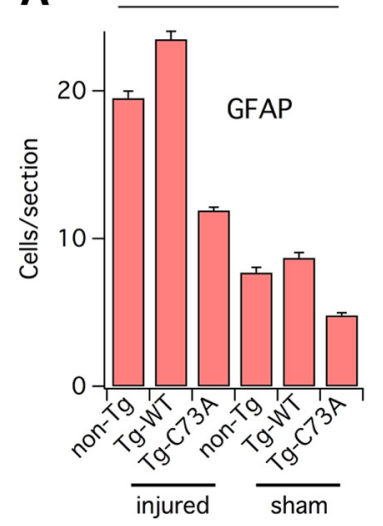

B

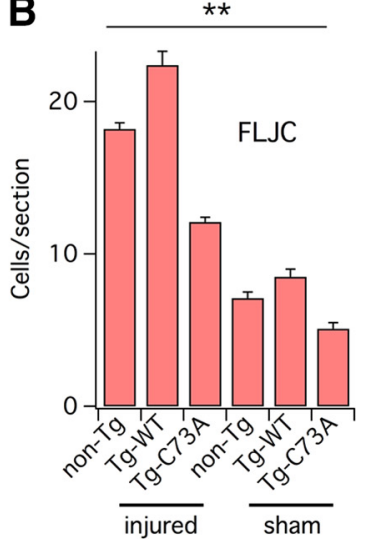

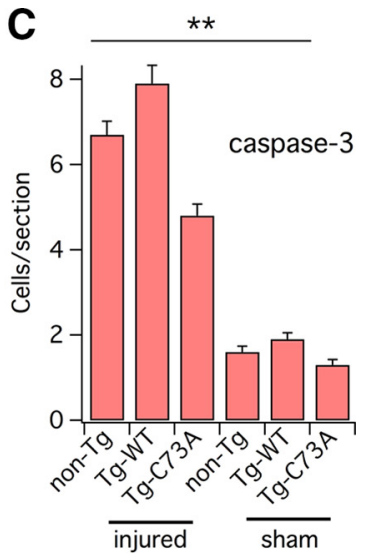

Figure 8. Typical lesions of TBI are ameliorated in the hippocampi of Tg-C73A mice. A, Mean number of cells positive for GFAP antibody per hippocampal section of the indicated genotypes at $7 \mathrm{dpi} . p<0.0001$ with pairwise comparisons all statistically significant except sham non-Tg versus sham Tg-WT (one-way ANOVA/Tukey's post hoc test). Each single mean was calculated from 18 sections ( 3 brains, 2 fields of view/section). B . Mean number of cells positive for FLC per hippocampal section of the indicated genotypes at 7 dpi. $p<0.0001$ with pairwise comparisons all statistically significant except sham non-Tg versus sham Tg-WT and sham non-Tg versus sham Tg-C73A (one-way ANOVA/Tukey's post hoc test). Each single mean was calculated from 8-12 sections (2-3 brains, 2 fields of view/section). C, Mean number of cells positive for activated caspase-3 antibody per hippocampal section of the indicated genotypes at $7 \mathrm{dpi}$. $p<0.0001$ with pairwise comparisons all statistically significant except sham non-Tg versus sham Tg-WT, non-Tg versus sham Tg-C73A, and sham Tg-WT versus sham Tg-C73A (one-way ANOVA/Tukey's post hoc test). Each single mean was calculated from 18 sections ( 3 brains, 2 fields of view/section). ${ }^{* *} p<0.01$.

trigger the release of ROS, the transgenic mice are normal at baseline. In all groups of mice, latencies reached a peak around the first week after injury and then either remained stable or, as in the case of Tg-C73A, moderately decreased. This trend probably reflects the fact that the animals were getting acquainted to the device (in fact, latencies were shorter presurgery, probably because the animals experienced the device for the first time; Fig. $6 A)$. We and others have observed this behavior in previous stud- 
Table 1. Cortical sections stainings

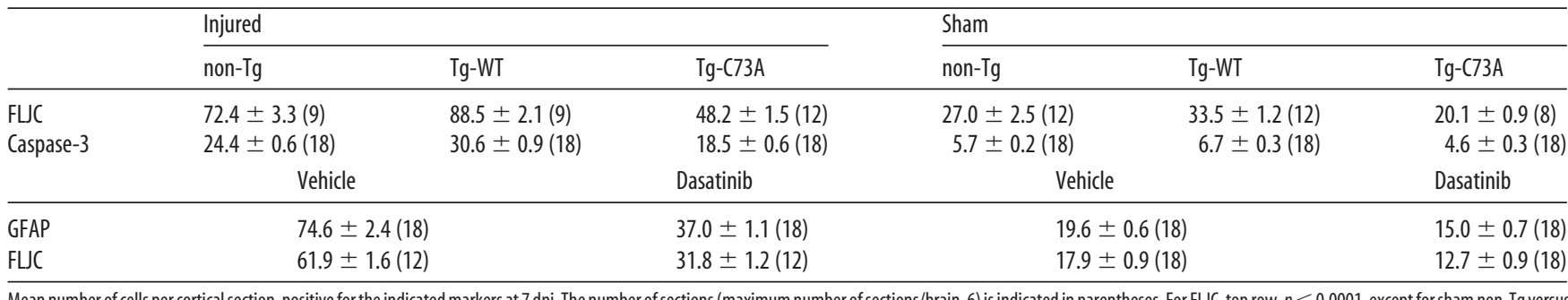

Mean number of cells per cortical section, positive for the indicated markers at $7 \mathrm{dpi}$. The number of sections (maximum number of sections/brain, 6 ) is indicated in parentheses. For FUC, top row, $p<0.0001$, except for sham non-Tg versus sham Tg-WT and sham non-Tg versus sham Tg-C73A (not statistically significant). For caspase-3, $p<0.0001$, except for sham non-Tg versus sham Tg-WT, sham non-Tg versus sham Tg-C73A, and sham Tg-WT versus sham Tg-C73A (not statistically significant). For GFAP, $p<0.0001$, except for sham vehicle versus sham dasatinib (not statistically significant). For FLIC, bottom row, $p<0.0001$, and all pairwise comparisons are statistically significant (one-way ANOVA/Tukey's post hoc test).

ies (Cernak et al., 2014; Chen et al., 2014; Rowe et al., 2014; Alder et al., 2016), and since it was independent of the injury, we did not investigate this matter further.

\section{Tg-C73A mice perform better than non-Tg and Tg-WT mice in the Morris water maze}

Spatial learning and memory were assessed in the MWM using independent groups of mice. As observed in the rotarod test, all mice behaved similarly in the presurgery trial using a visible platform, and therefore baseline adjustments were not performed (Fig. 6D). During the training period after surgery (Fig. 6E) and in the test of memory consolidation that was administered the day after the last training (Fig. 6G), injured Tg-C73A mice performed significantly better than non-Tg and Tg-WT, with the latter being the most cognitively impaired. Indeed, injured TgC73A animals did not exhibit any appreciable loss of cognitive function in the MWM (Fig. 6F, compare injured mice and shams). To exclude (or quantify) that impaired motor function could have affected the ability of the animals to reach the platform, we measured swimming speeds, which were comparable in the various groups of mice, suggesting that the improved out come in the $\mathrm{Tg}-\mathrm{C} 73 \mathrm{~A}$ mice was not due to increased activity (Fig. 6H).

\section{Typical histological lesions of TBI are reduced in cortex and hippocampus of $\mathrm{Tg}-\mathrm{C} 73 \mathrm{~A}$ mice}

Inflammation, disruption of axonal transport followed by axonal swelling, and finally degeneration and neuronal death are three hallmark lesions of TBI that affect many processes including motor function, memory, and spatial learning (Smith et al., 1991; Miyazaki et al., 1992; Hamm et al., 1993; Hicks et al., 1993; Dixon et al., 1999; Royo et al., 2003; Johnson et al., 2013; DeKosky et al., 2013). Therefore, we compared the extent of these lesions in coronal sections of the region of injury throughout the cortex and hippocampus that we stained against glial fibrillary acidic protein (cortex, Fig. 7; hippocampus, Fig. 8A), which, being a marker for glia (astrocytes) and since gliosis accompanies inflammation, provides indirect evidence for inflammation (Jacque et al., 1978; Vos et al., 2010); Fluoro-Jade C (FLJC, hippocampus, Fig. 8B; cortex, Table 1), a marker for neurodegeneration (Schmued et al., 1997); and activated caspase-3 (hippocampus, Fig. 8C; cortex, Table 1), a marker for neuronal apoptosis (caspase-3 staining colocalizes with NeuN but not GFAP; Beer et al., 2000; Clark et al., 2000; McEwen and Springer, 2005; Alder et al., 2016). Representative images of GFAP staining in cortical sections of the various genotypes at 7 and $21 \mathrm{dpi}$ along with quantitative analyses are shown in Figure 7. Thus, consistent with the course of a traumatic event, GFAP staining revealed the onset of an inflammatory process, remitting over time that was high in $\mathrm{Tg}$-WT and
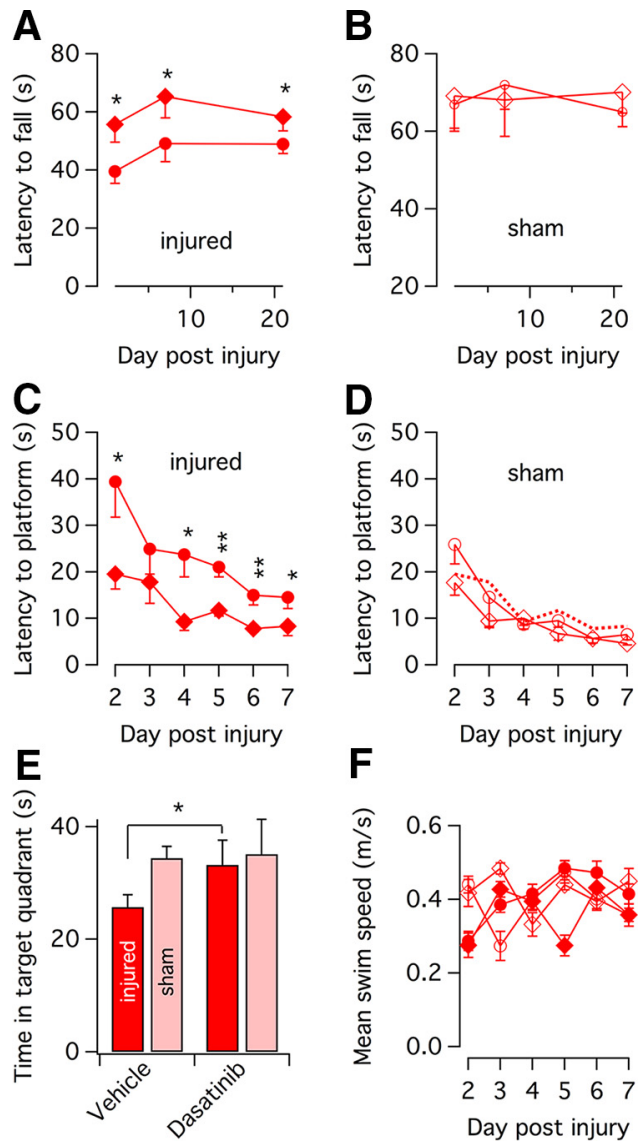

Figure 9. Dasatinib improves behavioral outcome in LFP-injured mice. $A$, Latency to fall from the rotating rod of non- $\mathrm{Tg}$ injured mice injected intraperitoneally daily with $25 \mathrm{mg} / \mathrm{kg}$ dasatinib (diamonds) or vehicle (circles). $p \leq 0.039$ for statistical comparisons at each individual dpi (one-tailed Student's $t$ test). In five experiments, $N=8$ and 8 animals for vehicle- and dasatinib-injected mice, respectively. $\boldsymbol{B}$, Latency to fall from the rotating rod of sham non- $\mathrm{Tg}$ mice injected with dasatinib (diamonds) or vehicle (circles). Differences between means are not statistically significant (one-tailed Student's $t$ test). In five experiments, $N=8$ and 7 animals for vehicle- and dasatinib-injected mice, respectively. $C$, Latency to reach the platform of injured non-Tg mice injected with dasatinib (diamonds) or vehicle (circles). Where indicated, $p \leq 0.045$ for statistical comparisons at each individual dpi (one-tailed Student's t test). In five experiments, $N=9$ and 9 animals for vehicle- and dasatinib-injected mice, respectively. $\boldsymbol{D}$, Latency to reach the platform of sham non-Tg mice treated with dasatinib (diamonds) or vehicle (circles). The dotted line indicates injured mice treated with dasatinib. Differences between means are not statistically significant (onetailed Student's $t$ test). In five experiments, $N=8$ and 8 animals for vehicle- and dasatinib-injected mice, respectively. $\boldsymbol{E}$, Consolidated memory retention test for the indicated groups of mice. $p=0.025$ (one-tailed Student's $t$ test). In five experiments, $N=9$ and 9 animals for vehicle- and dasatinibinjected mice respectively, and $N=8$ and 8 for their respective shams. $F$, Mean swimming speeds of injured (filled symbols) and sham (hollow symbols) mice treated with dasatinib (diamonds) or vehicle (circles). Differences between means are not statistically significant (one-way ANOVA). In five experiments, $N=9$ and 9 animals for vehicle- and dasatinib-injected mice, respectively, and $N=8$ and 8 for their respective shams. ${ }^{*} p<0.05 ;{ }^{* *} p<0.01$. 
low in Tg-C73A sections. Results of immunostaining in hippocampal sections at 7 dpi are summarized in Figure 8 and in cortical sections in Table 1 . In all cases, damage was maximal in Tg-WT and minimal in Tg-C73A brains underscoring the existence of a causative relationship between KNCB1 oxidation, tissue destruction, and behavioral deficit following the LFP injury. Thus, where KCNB1 oxidation was exacerbated, neuronal damage was increased and the outcome of TBI was severe, whereas where KCNB1 oxidation was suppressed, the outcome of TBI, along with tissue damage, were improved. We further notice that inflammation, neurodegeneration, and apoptosis were moderately more pronounced in the sham brains of $\mathrm{Tg}$-WT compared to non-Tg and Tg-C73A mice. This may indicate moderate oxidation in the shams, probably due to the surgery, or, alternatively, the existence of KCNB1independent mechanisms that contribute to tissue damage. We conclude that oxidation of KCNB1 channels resulting from TBI is an event that contributes toward tissue damage and impacts behavioral outcomes.

\section{Mice treated with dasatinib perform} better than vehicle mice in the rotarod

Previous in vitro studies showed that oxidation of hKCNB1 channels favors the activation of Src tyrosine kinases, which in turn initiate an apoptotic cascade (Fig. 1; Wu et al., 2013). Therefore, we sought to determine whether pharmacological strategies that act to inhibit the activities of Src kinases could improve neuronal lesions and behavioral outcome of LFP-injured animals. To this end we used dasatinib, an FDA-approved Src kinases inhibitor that is blood-brain barrier permeable and pharmacologically active in the brain (Porkka et al., 2008; Agarwal et al., 2012). Mice injected with dasatinib ( $25 \mathrm{mg} / \mathrm{kg}$ daily starting $2 \mathrm{~h}$ after surgery; Luo et al., 2006; Hasima and Aggarwal, 2012; Katsumata et al., 2012) or vehicle and their respective shams were subjected to the rotarod and the MWM protocols, and the results of these experiments are illustrated in Figure 9. Thus, dasatinib significantly increased latency to fall at all days after injury relative to vehicle-treated mice (Fig. 9A) and had no effect on sham animals (Fig. 9B).

\section{Mice treated with dasatinib performed better than vehicle mice in the Morris water maze}

During the $6 \mathrm{~d}$ training period (Figs. $9 C, D$ ) and in the memory retention test the following day (Fig. 9E), injured mice injected with dasatinib performed significantly better than vehicle mice. In fact, there was no significant difference in the behavioral responses of injured mice treated with the drug and the shams (Fig. 9D). Mean swimming speeds, displayed in Figure $9 F$, were similar in all groups, excluding that differences in the fitness of the animals might have impacted the outcome of the tests.

\section{Histological lesions of TBI are reduced in the brains of mice treated with dasatinib}

Cortical and hippocampal sections were stained with anticaspase-3 (Fig. 10, Table 1) and GFAP and FLJC (Fig. 11, Table 1). As expected, dasatinib treatment resulted in a marked decrease of the number of cells positive for the various markers compared to vehicle in both cortical (Fig. 10, Table 1) and hippocampal sections (Fig. 11). The number of positive cells to any marker was moderately higher in sham animals injected with vehicle compared to those injected with dasatinib (albeit these differences were generally not statistically significant). The protective effect of the drug in sham animals may reflect baseline oxidation of KCNB1 channels or, alternatively, inflammatory processes associated with the surgery. We conclude that inhibition of the activity of Src tyrosine kinases significantly ameliorates typical lesions of TBI, leading to improved motor function and spatial memory during the critical phase of the LFP injury.

\section{Oxidation of KCNB1 channels is associated with Src kinases activity}

To determine whether oxidation of KCNB1 channels was responsible for the activation of the Src kinases following the LFP injury and therefore link the effect of dasatinib on recovery post TBI to KCNB1 oxidation, we biochemically assessed the fraction of activated Src kinases in the brains of our mice using an antiphosphorylated Src family antibody that detects phosphorylation status of tyr416, a residue conserved in all members of the Src kinase family (Konig et al., 2008). Representative immunoblots of total and activated (phosphorylated) Src proteins in the brains of mice injected with vehicle or dasatinib and separately in the brains of non-Tg, Tg-WT, and Tg-C73A animals, along with densitometric analyses, are illustrated in Figure 12. Src activity was 
A

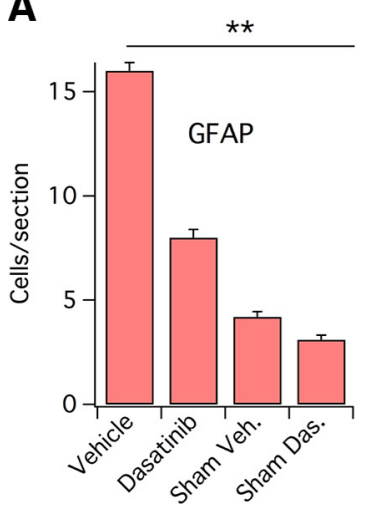

B

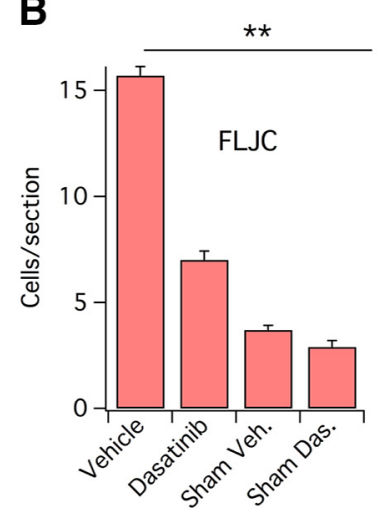

C

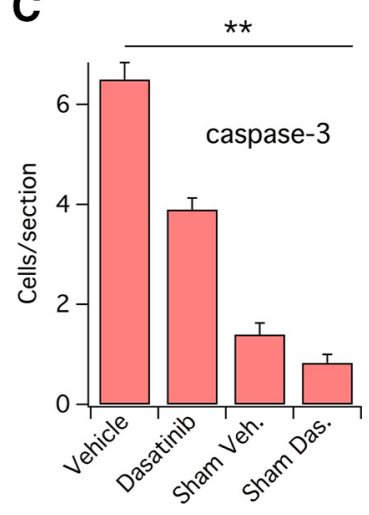

Figure 11. Typical lesions of TBI are ameliorated in the hippocampi of mice treated with dasatinib. A, Mean number of cells positive for GFAP per hippocampal section of the indicated groups of mice at $7 \mathrm{dpi}$. Each single mean was calculated from 18 sections ( 3 brains, 2 fields of view/section). B, Mean number of cells positive to FLC per hippocampal section of the indicated groups of mice at $7 \mathrm{dpi}$. Each single mean was calculated from 12-18 sections (2-3 brains, 2 fields of view/section). C, Mean number of cells positive to anti-caspase-3 per hippocampal section of the indicated groups of mice at $7 \mathrm{dpi}$. Each single mean was calculated from 12 sections ( 2 brains, 2 fields of view/section). In $A-C, p<0.0001$ with pairwise comparisons all statistically significant except sham vehicle versus sham dasatinib (one-way ANOVA/Tukey's post hoc test). ${ }^{* *} p<0.01$.

A
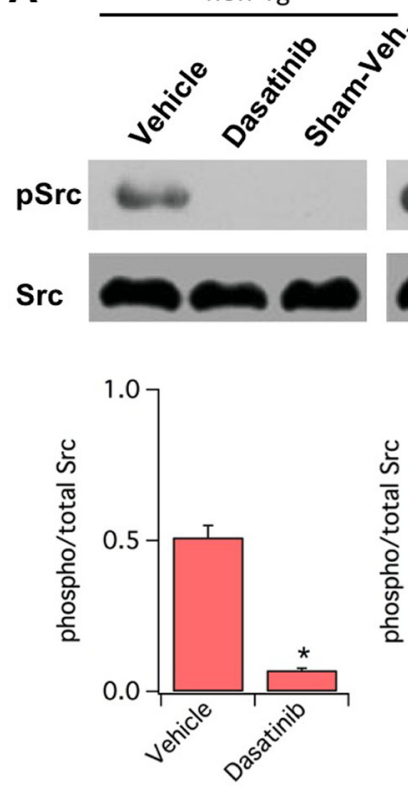
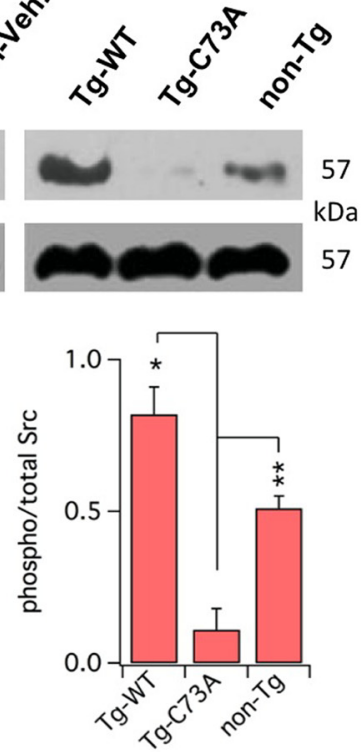

B
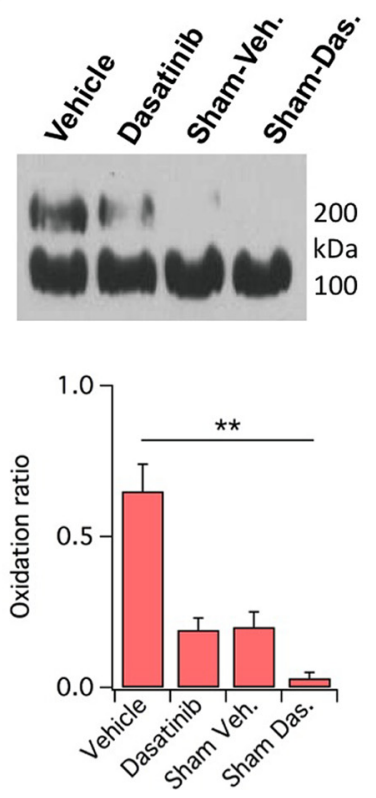

Figure 12. The activity of Src kinases is negligible in the brains of Tg-C73A mice. A, Representative Western blot showing total and phosphorylated Src (pSrc) in the brains of injured non-Tg mice injected with vehicle or dasatinib, in the brains of vehicle sham non-Tg mice, and in the brains of injured Tg-WT, $\mathrm{Tg}-\mathrm{C} 73 \mathrm{~A}$, and non-Tg mice. Animals were killed at $7 \mathrm{dpi}$, and brain lysates were immunoprecipitated with an antibody that recognizes total Src and immunoblotted with an antibody that recognizes Src phosphorylated at tyr416. Densitometric quantifications are expressed as the fractions of activated Src kinases (phosphorylated Src normalized to total $\mathrm{Src}$ ). $p=0.0017$ for vehicle/dasatinib (one-tailed Student's $t$ test; $N=3$ experiments); $p=0.011$ for non- $\mathrm{Tg}$ $\mathrm{Tg}$-WT, and Tg-C73A with pairwise comparisons all statistically significant except Tg-WT versus non-Tg, (one-way ANOVA/Tukey's post hoc test; $N=3$ experiments). $\boldsymbol{B}$, Representative Western blot showing KCNB1 oligomers in the brains of injured and sham mice injected with vehicle or dasatinib and densitometric quantification of three experiments. Animals were killed at $7 \mathrm{dpi}$ and immunoblotted with anti-KCNB1 antibody. $p=0.00045$ with pairwise comparisons all statistically significant except injured dasatinib versus sham vehicle and sham vehicle versus sham dasatinib (one-way ANOVA/Tukey's post hoc test). ${ }^{*} p<0.05$; ${ }^{* *} p<$ 0.01 .

significantly inhibited in animals subjected to dasatinib therapy, confirming that dasatinib acts upon the Src pathway (Fig. 12A). Most importantly, the fraction of activated Src kinases was decreased in the brains of Tg-C73A animals and increased in the brains of Tg-WT animals compared to control (Fig. 12A). Previous studies have indicated that Src kinases act to induce oxidative stress, possibly via a pathway that destabilizes mitochondria (Wu et al., 2013). This implies that KCNB1 oxidation should be low in mice treated with dasatinib. Indeed, the amounts of KCNB1 oligomers were significantly decreased in the brains of mice treated with the drug compared to vehicle, and in fact, their amounts were comparable to those of sham mice (Fig. 12B).

Together these data indicate that in the brains where oxidation of KCNB1 was prevented, the activity of Src kinases was negligible, and vice versa, in the brains where Src activity was inhibited, oxidation of KCNB1 channels was also low. We conclude that there is a causative relationship between oxidation of KCNB1 channels and Src tyrosine kinases activities.

\section{Discussion}

To determine the role that oxidation of $\mathrm{KCNB} 1 \mathrm{~K}^{+}$channels has for the function of the brain, we developed a transgenic mouse expressing a KCNB1 mutant (C73A) resistant to redox and pursued a pharmacological approach that directly impinges on the apoptotic pathway activated in response to oxidation of the channel. We found that decreasing the amount of oxidizable KCNB1 channels by genetic means is strongly protective in a mouse model of moderate TBI, a condition characterized by high oxidative stress. Thus, neuronal damage induced by the LFP injury was markedly reduced in Tg-C73A mice, and consequently, the animals exhibited improved behavioral outcome after TBI. Moreover, the detrimental effects of the neurotoxic pathway activated in response to KCNB1 oxidation could be neutralized by dasatinib, which ameliorated the devastating effects of TBI during both the primary and secondary injury processes. Furthermore, Src kinase activities were significantly depressed in the brains of $\mathrm{Tg}-\mathrm{C} 73 \mathrm{~A}$ mice, and, vice versa, the drug was associated with small amounts of oxidized channels. Overall, these findings demonstrate that oxidation of KCNB1 channels represents a mechanism of cognitive and functional impairment in vertebrates and further validate a molecular model for its toxicity that emerged from in vitro evidence. Despite a large volume of research, no medication has been proven effective for the treatment of TBI in humans. Protein kinases are one of the most investigated drug targets by the pharmaceutical industry, but the development of kinase-based therapies for brain diseases remains a challenge (Chico et al., 2009). Thus these findings not only underscore the pathological nature of oxidation of KCNB1 channels in TBI, but they may further suggest a new 
therapeutic approach for a condition that affects millions worldwide.

One general problem with transgenic approaches is the potential side effects of protein overexpression. The mice used in this investigation were normal in size and weight, developed normally, did not present any tissue damage, did not show any apparent phenotype, and, limited to the cognitive abilities assessed in this study, they were normal. Thus, it appears that a moderate KCNB1 gain of function is well tolerated in the brain even though we cannot completely exclude that the transgenic mice may have developed some sort of cognitive decompensation that went undetected in our investigations. These findings also argue against the idea that augmented KCNB1 current is proapoptotic, as suggested by some in vitro studies (for review, see Sesti et al., 2014). Moreover, since the $\mathrm{N}$ terminus and the $\mathrm{C}$ terminus of the channel physically interact during the channel's activation (Ju et al., 2003; Kobrinsky et al., 2006) and oligomerization probably links the two termini together through disulfide bridges, it is possible that the antiapoptotic effect of some KCNB1 inhibitors (Liu et al., 2013; Zhou et al., 2016) stems from their ability to prevent oligomerization rather than conduction, or, alternatively, as in the case of heme oxygenase-1 in in vitro models of Alzheimer's disease, through interfering with KCNB1 regulatory pathways (Hettiarachchi et al., 2014). In contrast, the effects of the LFP injury were markedly aggravated in Tg-WT mice compared to non- $\mathrm{Tg}$ mice, suggesting that the increased amount of oxidized KCNB1 channels in the former is proportional to the extent of the neuronal damage and behavioral deficits. Speca et al. (2014) have shown that in KCNB1 KO mice the absence of KCNB1 current causes hyperexcitability, which in turn correlates with cognitive impairment and susceptibility to seizure. Oxidized KCNB1 channels do not conduct current (Cotella et al., 2012; Frazzini et al., 2016), and this may explain the cognitive impairment of LFPinjured mice. On the other hand, the potent effect of dasatinib would argue that neuronal damage is the underlying cause, but it must be considered that inhibition of Src tyrosine kinases results in lower levels of oxidized - and therefore nonconducting KCNB1 channels. Thus, it is likely that decreased current and apoptotic stimuli both contribute to the neuronal and behavioral deficits observed in injured mice, and future investigations will dissect the individual contribution of each to TBI.

Oxidation of a $\mathrm{K}^{+}$channel as a mechanism of neuronal vulnerability was initially demonstrated in Caenorhabditis elegans (Cai and Sesti, 2009). The channel that undergoes oxidation in the worm, KVS-1, is a homolog of KCNB1 (Rojas et al., 2008), and in both channels the effects of oxidation are mediated by conserved cysteine residues, cys 113 in KVS-1 and cys73 in KCNB1. The findings reported here that show that oxidation of $\mathrm{K}^{+}$channels contribute to cognitive impairment underscore the high degree of conservation of this mechanism of neuronal vulnerability and further broaden its potential relevance. For example, it is well established that the aging hippocampus of rodents develops hyperexcitability (Landfield et al., 1986; Barnes et al., 1987; Barnes, 1994; Papatheodoropoulos and Kostopoulos, 1996), and it may not be coincidental that KCNB1 undergoes oxidation in the brains of naturally aging mice (Cotella et al., 2012). Moreover, KCNB1 channels are oxidized in hippocampal neurons of the $3 \mathrm{x}-\mathrm{Tg}-\mathrm{AD}$ mouse where they promote hyperexcitability (Frazzini et al., 2016), while inhibition of Src kinases attenuates microgliosis in BV2 murine cells incubated with $\beta$-amyloid oligomers (Dhawan and Combs, 2012). In summary, the evidence presented here would argue that oxidation of $\mathrm{KCNB} 1$ channels is a mechanism that contributes to cognitive deficit in normal aging as well in Alzheimer's disease-albeit to different extents — and by analogy, that dasatinib may represent a valid model of therapeutic intervention in neurodegenerative disease.

\section{References}

Agarwal S, Mittapalli RK, Zellmer DM, Gallardo JL, Donelson R, Seiler C, Decker SA, Santacruz KS, Pokorny JL, Sarkaria JN, Elmquist WF, Ohlfest JR (2012) Active efflux of Dasatinib from the brain limits efficacy against murine glioblastoma: broad implications for the clinical use of molecularly targeted agents. Mol Cancer Ther 11:2183-2192. CrossRef Medline

Aigner L, Arber S, Kapfhammer JP, Laux T, Schneider C, Botteri F, Brenner HR, Caroni P (1995) Overexpression of the neural growth-associated protein GAP-43 induces nerve sprouting in the adult nervous system of transgenic mice. Cell 83:269-278. CrossRef Medline

Alder J, Fujioka W, Lifshitz J, Crockett DP, Thakker-Varia S (2011) Lateral fluid percussion: model of traumatic brain injury in mice. J Vis Exp 54: e3063. Medline

Alder J, Fujioka W, Giarratana A, Wissocki J, Thakkar K, Vuong P, Patel B, Chakraborty T, Elsabeh R, Parikh A, Girn HS, Crockett D, Thakker-Varia $S$ (2016) Genetic and pharmacological intervention of the p75NTR pathway alters morphological and behavioural recovery following traumatic brain injury in mice. Brain Inj 30:48-65. CrossRef Medline

Barnes CA (1994) Normal aging: regionally specific changes in hippocampal synaptic transmission. Trends Neurosci 17:13-18. CrossRef Medline

Barnes CA, Rao G, McNaughton BL (1987) Increased electrotonic coupling in aged rat hippocampus: a possible mechanism for cellular excitability changes. J Comp Neurol 259:549-558. CrossRef Medline

Beer R, Franz G, Srinivasan A, Hayes RL, Pike BR, Newcomb JK, Zhao X, Schmutzhard E, Poewe W, Kampfl A (2000) Temporal profile and cell subtype distribution of activated caspase- 3 following experimental traumatic brain injury. J Neurochem 75:1264-1273. Medline

Cai SQ, Sesti F (2009) Oxidation of a potassium channel causes progressive sensory function loss during aging. Nat Neurosci 12:611-617. CrossRef Medline

Cernak I, Wing ID, Davidsson J, Plantman S (2014) A novel mouse model of penetrating brain injury. Front Neurol 5:209. Medline

Chen Y, Mao H, Yang KH, Abel T, Meaney DF (2014) A modified controlled cortical impact technique to model mild traumatic brain injury mechanics in mice. Front Neurol 5:100. Medline

Chico LK, Van Eldik LJ, Watterson DM (2009) Targeting protein kinases in central nervous system disorders. Nat Rev Drug Discov 8:892-909. CrossRef Medline

Chou JL, Shenoy DV, Thomas N, Choudhary PK, Laferla FM, Goodman SR, Breen GA (2011) Early dysregulation of the mitochondrial proteome in a mouse model of Alzheimer's disease. J Proteomics 74:466-479. CrossRef Medline

Clark RS, Kochanek PM, Watkins SC, Chen M, Dixon CE, Seidberg NA, Melick J, Loeffert JE, Nathaniel PD, Jin KL, Graham SH (2000) Caspase-3 mediated neuronal death after traumatic brain injury in rats. J Neurochem 74:740-753. Medline

Corps KN, Roth TL, McGavern DB (2015) Inflammation and neuroprotection in traumatic brain injury. JAMA Neurol 72:355-362. CrossRef Medline

Cotella D, Hernandez-Enriquez B, Wu X, Li R, Pan Z, Leveille J, Link CD, Oddo S, Sesti $\mathrm{F}$ (2012) Toxic role of $\mathrm{k}+$ channel oxidation in mammalian brain. J Neurosci 32:4133-4144. CrossRef Medline

DeKosky ST, Blennow K, Ikonomovic MD, Gandy S (2013) Acute and chronic traumatic encephalopathies: pathogenesis and biomarkers. Nat Rev Neurol 9:192-200. CrossRef Medline

Dhawan G, Combs CK (2012) Inhibition of Src kinase activity attenuates amyloid associated microgliosis in a murine model of Alzheimer's disease. J Neuroinflammation 9:117. Medline

Dixon CE, Kraus MF, Kline AE, Ma X, Yan HQ, Griffith RG, Wolfson BM, Marion DW (1999) Amantadine improves water maze performance without affecting motor behavior following traumatic brain injury in rats. Restor Neurol Neurosci 14:285-294. Medline

Domeniconi M, Hempstead BL, Chao MV (2007) Pro-NGF secreted by astrocytes promotes motor neuron cell death. Mol Cell Neurosci 34:271279. CrossRef Medline

Du J, Haak LL, Phillips-Tansey E, Russell JT, McBain CJ (2000) Frequency- 
dependent regulation of rat hippocampal somato-dendritic excitability by the K+ channel subunit Kv2.1. J Physiol 522:19-31. CrossRef Medline

Fox PD, Loftus RJ, Tamkun MM (2013) Regulation of Kv2.1 K(+) conductance by cell surface channel density. J Neurosci 33:1259-1270. CrossRef Medline

Frazzini V, Guarnieri S, Bomba M, Navarra R, Morabito C, Mariggiò MA, Sensi SL (2016) Altered Kv2.1 functioning promotes increased excitability in hippocampal neurons of an Alzheimer's disease mouse model. Cell Death Dis 7:e2100. CrossRef Medline

Hamm RJ, Lyeth BG, Jenkins LW, O’Dell DM, Pike BR (1993) Selective cognitive impairment following traumatic brain injury in rats. Behav Brain Res 59:169-173. CrossRef Medline

Hasima N, Aggarwal BB (2012) Cancer-linked targets modulated by curcumin. Int J Biochem Mol Biol 3:328-351. Medline

Hettiarachchi N, Dallas M, Al-Owais M, Griffiths H, Hooper N, Scragg J, Boyle J, Peers C (2014) Heme oxygenase-1 protects against Alzheimer's amyloid-beta(1-42)-induced toxicity via carbon monoxide production. Cell Death Dis 5:e1569. CrossRef Medline

Hicks RR, Smith DH, Lowenstein DH, Saint Marie R, McIntosh TK (1993) Mild experimental brain injury in the rat induces cognitive deficits associated with regional neuronal loss in the hippocampus. J Neurotrauma 10:405-414. CrossRef Medline

Hiebert JB, Shen Q, Thimmesch AR, Pierce JD (2015) Traumatic brain injury and mitochondrial dysfunction. Am J Med Sci 350:132-138. CrossRef Medline

Hille B (2001) Ionic channels of excitable membranes, Ed 3. Sunderland, MA: Sinauer.

Jacque CM, Vinner C, Kujas M, Raoul M, Racadot J, Baumann NA (1978) Determination of glial fibrillary acidic protein (GFAP) in human brain tumors. J Neurol Sci 35:147-155. CrossRef Medline

Johnson VE, Stewart W, Smith DH (2013) Axonal pathology in traumatic brain injury. Exp Neurol 246:35-43. Medline

Ju M, Stevens L, Leadbitter E, Wray D (2003) The Roles of N- and C-terminal determinants in the activation of the Kv2.1 potassium channel. J Biol Chem 278:12769-12778. CrossRef Medline

Katsumata R, Ishigaki S, Katsuno M, Kawai K, Sone J, Huang Z, Adachi H, Tanaka F, Urano F, Sobue G (2012) c-Abl inhibition delays motor neuron degeneration in the G93A mouse, an animal model of amyotrophic lateral sclerosis. PLoS One 7:e46185. CrossRef Medline

Kobrinsky E, Stevens L, Kazmi Y, Wray D, Soldatov NM (2006) Molecular rearrangements of the Kv2.1 potassium channel termini associated with voltage gating. J Biol Chem 281:19233-19240. CrossRef Medline

Konig H, Copland M, Chu S, Jove R, Holyoake TL, Bhatia R (2008) Effects of dasatinib on SRC kinase activity and downstream intracellular signaling in primitive chronic myelogenous leukemia hematopoietic cells. Cancer Res 68:9624-9633. CrossRef Medline

Landfield PW, Pitler TA, Applegate MD (1986) The effects of high Mg2+to-Ca2 + ratios on frequency potentiation in hippocampal slices of young and aged rats. J Neurophysiol 56:797-811. Medline

Laurer HL, McIntosh TK (1999) Experimental models of brain trauma. Curr Opin Neurol 12:715-721. CrossRef Medline

Lifshitz J (2008) Fluid percussion injury model. In: Animal models of acute neurological injuries (Chen J, Xu ZC, Xu XM, Zhang JH, eds), pp 369384. New York: Humana.

Lim ST, Antonucci DE, Scannevin RH, Trimmer JS (2000) A novel targeting signal for proximal clustering of the Kv2.1 K+ channel in hippocampal neurons. Neuron 25:385-397. CrossRef Medline

Liu H, Liu J, Liang S, Xiong H (2013) Plasma gelsolin protects HIV-1 gp120induced neuronal injury via voltage-gated $\mathrm{K}$ channel Kv2.1. Moll Cell Neurosci 57:73-82. Medline

Longhi L, Saatman KE, Fujimoto S, Raghupathi R, Meaney DF, Davis J, McMillan BS, Conte V, Laurer HL, Stein S, Stocchetti N, McIntosh TK (2005) Temporal window of vulnerability to repetitive experimental concussive brain injury. Neurosurgery 56:364-374; discussion 364-374. CrossRef Medline

Luo FR, Yang Z, Camuso A, Smykla R, McGlinchey K, Fager K, Flefleh C, Castaneda S, Inigo I, Kan D, Wen ML, Kramer R, Blackwood-Chirchir A, Lee FY (2006) Dasatinib (BMS-354825) pharmacokinetics and pharmacodynamic biomarkers in animal models predict optimal clinical exposure. Clin Cancer Res 12:7180-7186. CrossRef Medline

Masel BE, DeWitt DS (2010) Traumatic brain injury: a disease process, not an event. J Neurotrauma 27:1529-1540. CrossRef Medline
McEwen ML, Springer JE (2005) A mapping study of caspase-3 activation following acute spinal cord contusion in rats. J Histochem Cytochem 53:809-819. CrossRef Medline

McIntosh TK, Vink R, Noble L, Yamakami I, Fernyak S, Soares H, Faden AL (1989) Traumatic brain injury in the rat: characterization of a lateral fluid-percussion model. Neuroscience 28:233-244. CrossRef Medline

McManus MJ, Murphy MP, Franklin JL (2011) The mitochondria-targeted antioxidant MitoQ prevents loss of spatial memory retention and early neuropathology in a transgenic mouse model of Alzheimer's disease. J Neurosci 31:15703-15715. CrossRef Medline

Miyazaki S, Katayama Y, Lyeth BG, Jenkins LW, DeWitt DS, Goldberg SJ, Newlon PG, Hayes RL (1992) Enduring suppression of hippocampal long-term potentiation following traumatic brain injury in rat. Brain Res 585:335-339. CrossRef Medline

Murakoshi H, Trimmer JS (1999) Identification of the Kv2.1 K+ channel as a major component of the delayed rectifier $\mathrm{K}+$ current in rat hippocampal neurons. J Neurosci 19:1728-1735. Medline

O'Connell KM, Rolig AS, Whitesell JD, Tamkun MM (2006) Kv2.1 potassium channels are retained within dynamic cell surface microdomains that are defined by a perimeter fence. J Neurosci 26:9609-9618. CrossRef Medline

O'Connell KM, Loftus R, Tamkun MM (2010) Localization-dependent activity of the Kv2.1 delayed-rectifier K+ channel. Proc Natl Acad Sci U S A 107:12351-12356. CrossRef Medline

Oddo S, Caccamo A, Shepherd JD, Murphy MP, Golde TE, Kayed R, Metherate R, Mattson MP, Akbari Y, LaFerla FM (2003) Triple-transgenic model of Alzheimer's disease with plaques and tangles: intracellular Abeta and synaptic dysfunction. Neuron 39:409-421. CrossRef Medline

Papatheodoropoulos C, Kostopoulos G (1996) Age-related changes in excitability and recurrent inhibition in the rat CA1 hippocampal region. Eur J Neurosci 8:510-520. CrossRef Medline

Patel R, Sesti F (2016) Oxidation of ion channels in the aging nervous system. Brain Res 1639:174-185. CrossRef Medline

Porkka K, Koskenvesa P, Lundán T, Rimpiläinen J, Mustjoki S, Smykla R, Wild R, Luo R, Arnan M, Brethon B, Eccersley L, Hjorth-Hansen H, Höglund M, Klamova H, Knutsen H, Parikh S, Raffoux E, Gruber F, Brito-Babapulle F, Dombret H, et al. (2008) Dasatinib crosses the blood-brain barrier and is an efficient therapy for central nervous system Philadelphia chromosome-positive leukemia. Blood 112:1005-1012. CrossRef Medline

Redman PT, He K, Hartnett KA, Jefferson BS, Hu L, Rosenberg PA, Levitan ES, Aizenman E (2007) Apoptotic surge of potassium currents is mediated by p38 phosphorylation of Kv2.1. Proc Natl Acad Sci U S A 104: 3568-3573. CrossRef Medline

Rhodes KJ, Keilbaugh SA, Barrezueta NX, Lopez KL, Trimmer JS (1995) Association and colocalization of $\mathrm{K}+$ channel alpha- and beta-subunit polypeptides in rat brain. J Neurosci 15:5360-5371. Medline

Rojas P, Garst-Orozco J, Baban B, de Santiago-Castillo JA, Covarrubias M, Salkoff L (2008) Cumulative activation of voltage-dependent KVS-1 potassium channels. J Neurosci 28:757-765. CrossRef Medline

Roth TL, Nayak D, Atanasijevic T, Koretsky AP, Latour LL, McGavern DB (2014) Transcranial amelioration of inflammation and cell death after brain injury. Nature 505:223-228. CrossRef Medline

Rowe RK, Harrison JL, O’Hara BF, Lifshitz J (2014) Recovery of neurological function despite immediate sleep disruption following diffuse brain injury in the mouse: clinical relevance to medically untreated concussion. Sleep 37:743-752. Medline

Royo NC, Schouten JW, Fulp CT, Shimizu S, Marklund N, Graham DI, McIntosh TK (2003) From cell death to neuronal regeneration: building a new brain after traumatic brain injury. J Neuropathol Exp Neurol 62: 801-811. CrossRef Medline

Sarmiere PD, Weigle CM, Tamkun MM (2008) The Kv2.1 K+ channel targets to the axon initial segment of hippocampal and cortical neurons in culture and in situ. BMC Neurosci 9:112. CrossRef Medline

Schmued LC, Albertson C, Slikker WJ Jr (1997) Fluoro-Jade: a novel fluorochrome for the sensitive and reliable histochemical localization of neuronal degeneration. Brain Res 751:37-46. CrossRef Medline

Sensi SL, Rapposelli IG, Frazzini V, Mascetra N (2008) Altered oxidantmediated intraneuronal zinc mobilization in a triple transgenic mouse model of Alzheimer's disease. Exp Gerontol 43:488-492. CrossRef Medline 
Sesti F, Wu X, Liu S (2014) Oxidation of KCNB1 K(+) channels in central nervous system and beyond. World J Biol Chem 5:85-92. Medline

Shen Q, Hiebert JB, Hartwell J, Thimmesch AR, Pierce JD (epub ahead of print May 31, 2016) Systematic review of traumatic brain injury and the impact of antioxidant therapy on clinical outcomes. Worldviews Evid Based Nurs. doi: 10.1111/wvn.12167. Medline

Smith DH, Okiyama K, Thomas MJ, Claussen B, McIntosh TK (1991) Evaluation of memory dysfunction following experimental brain injury using the Morris water maze. J Neurotrauma 8:259-269. CrossRef Medline

Smith DH, Soares HD, Pierce JS, Perlman KG, Saatman KE, Meaney DF, Dixon CE, McIntosh TK (1995) A model of parasagittal controlled cortical impact in the mouse: cognitive and histopathologic effects. J Neurotrauma 12:169-178. CrossRef Medline

Smith IF, Hitt B, Green KN, Oddo S, LaFerla FM (2005) Enhanced caffeineinduced $\mathrm{Ca} 2+$ release in the $3 \times \mathrm{Tg}-\mathrm{AD}$ mouse model of Alzheimer's disease. J Neurochem 94:1711-1718. CrossRef Medline

Speca DJ, Ogata G, Mandikian D, Bishop HI, Wiler SW, Eum K, Wenzel HJ, Doisy ET, Matt L, Campi KL, Golub MS, Nerbonne JM, Hell JW, Trainor BC, Sack JT, Schwartzkroin PA, Trimmer JS (2014) Deletion of the Kv2.1 delayed rectifier potassium channel leads to neuronal and behavioral hyperexcitability. Genes Brain Behav 13:394-408. CrossRef Medline Thakker-Varia S, Alder J, Crozier RA, Plummer MR, Black IB (2001) Rab3A is required for brain-derived neurotrophic factor-induced synaptic plasticity: transcriptional analysis at the population and single-cell levels. J Neurosci 21:6782-6790. Medline

Thompson HJ, Lifshitz J, Marklund N, Grady MS, Graham DI, Hovda DA, McIntosh TK (2005) Lateral fluid percussion brain injury: a 15-year review and evaluation. J Neurotrauma 22:42-75. CrossRef Medline

Vos PE, Jacobs B, Andriessen TM, Lamers KJ, Borm GF, Beems T, Edwards M, Rosmalen CF, Vissers JL (2010) GFAP and S100B are biomarkers of traumatic brain injury: an observational cohort study. Neurology 75: 1786-1793. CrossRef Medline

Wu X, Hernandez-Enriquez B, Banas M, Xu R, Sesti F (2013) Molecular Mechanisms Underlying the Apoptotic Effect of KCNB1 K+ Channel Oxidation. J Biol Chem 288:4128-4134. CrossRef Medline

Yao J, Irwin RW, Zhao L, Nilsen J, Hamilton RT, Brinton RD (2009) Mitochondrial bioenergetic deficit precedes Alzheimer's pathology in female mouse model of Alzheimer's disease. Proc Natl Acad Sci U S A 106: 14670-14675. CrossRef Medline

Zhou TT, Quan LL, Chen LP, Du T, Sun KX, Zhang JC, Yu L, Li Y, Wan P, Chen LL, Jiang BH, Hu LH, Chen J, Shen X (2016) SP6616 as a new Kv2.1 channel inhibitor efficiently promotes beta-cell survival involving both PKC/Erk1/2 and CaM/PI3K/Akt signaling pathways. Cell Death Dis 7:e2216. CrossRef Medline 